\title{
Human Hepatocyte Nuclear Factor 4- $\alpha$ encodes isoforms with distinct transcriptional functions
}

Élie Lambert ${ }^{1}$, Jean-Philippe Babeu ${ }^{1}$, Joël Simoneau², Dominique Lévesque, Émilie Jolibois, Michelle Scott ${ }^{2}$, François Boudreau ${ }^{\text {l\# }}$ and François-Michel Boisvert ${ }^{\text {I\# }}$

${ }^{1}$ Department of Anatomy and Cell Biology, Université de Sherbrooke,

${ }^{2}$ Department of Biochemistry, Université de Sherbrooke,

3201 rue Jean-Mignault

Sherbrooke, Québec, J1E 4K8, Canada

Phone: 819-821-8000 Ext.75430

Fax: 819-820-6831

${ }^{\#}$ Co-corresponding authors: François Boudreau and François-Michel Boisvert

Email: francois.boudreau@usherbrooke and fm.boisvert@usherbrooke.ca

RUNNING TITLE: The functions of HNF4- $\alpha$ isoforms.

KEYWORDS: HNF4 $\alpha$, nuclear receptors, transcription, proteomics, protein isoforms 


\section{SUMMARY}

$\mathrm{HNF} 4 \alpha$ is a nuclear receptor produced as 12 isoforms from two promoters by alternative splicing. In order to characterize the transcriptional capacities of all $12 \mathrm{HNF} 4 \alpha$ isoforms, stable lines expressing each isoform were generated. The entire transcriptome associated with each isoform was analyzed as well as their respective interacting proteome. Major differences were noted in the transcriptional function of these isoforms. The $\alpha 1$ and $\alpha 2$ isoforms were the most potent regulators of gene expression while the $\alpha 3$ isoform exhibited significantly reduced activity. The $\alpha 4, \alpha 5$ and $\alpha 6$ isoforms, which use an alternative first exon, were characterized for the first time, and showed a greatly reduced transcriptional potential with an inability to recognize the consensus response element of HNF4 $\alpha$. Several transcription factors and coregulators were identified as potential specific partners for certain HNF4 $\alpha$ isoforms. An analysis integrating the vast amount of omics data enabled the identification of transcriptional regulatory mechanisms specific to certain $\mathrm{HNF} 4 \alpha$ isoforms, hence demonstrating the importance of considering all isoforms given their seemingly diverse functions. 


\section{INTRODUCTION}

Nuclear receptors (NR) represent a class of transcription factors that encompasses 48 proteins in humans (Zhang et al., 2004). The nomenclature surrounding the superfamily of NR, based on their phylogeny, consists of six subfamilies comprised of several groups (Nuclear Receptors Nomenclature Committee, 1999). NR share a structural organization of five to six distinct regions designated from A to $\mathrm{F}$ (Robinson-Rechavi et al., 2003). The A/B region, located at the $\mathrm{N}$-terminal end, is highly variable between the various NR. It typically contains an AF-1 transactivation region (Activation Function) which is active independently of ligand binding and allows the interaction of the receptor with various coregulators and other transcription factors (Lavery and McEwan, 2005). The $\mathrm{C}$ domain, or DNA-binding domain (DBD), is the most conserved among NR. It allows the recognition of specific DNA response elements via two cysteine-rich zinc finger motifs (C-X2-C-X13-C-X2-C and C-X5-C-X9-C-X2-C) (RobinsonRechavi et al., 2003). These response elements are composed of repeated or inverted hexameric DNA sequences and separated by linkers varying from one to five nucleotides in length (Khorasanizadeh and Rastinejad, 2001). The D region, also called hinge region, is less conserved and its main function is to facilitate free rotation between the DBD and the ligand binding domain (LBD). A nuclear localization signal (NLS) contained in this region participates in the regulation of the subcellular distribution of NR (Germain et al., 2006). The E domain, or ligand binding domain (LBD), consists of a hydrophobic pouch for binding a multitude of small lipophilic molecules such as steroid hormones, phospholipids, fatty acids and xenobiotics (Pawlak et al., 2012). Some NR for which no ligand has yet been identified are considered orphan receptors (Giguere, 1999). A second AF-2 activator region is located in the LBD. In contrast to the AF-1 region, the activity of the AF-2 region is dependent on ligand binding to LBD. This induces a conformational change in the LBD, generating a pouch that can interact with the LXXLL motif present on a host of transcriptional coactivators (Heery et al., 1997). The LBD, like the DBD, contains an important interface for receptor dimerization. Finally, at the Cterminus of the NR is the F domain. Because of its highly variable sequence, the exact function of the F domain remains to be established and several NR have no F domain (Patel and Skafar, 2015). Nevertheless, the deletion of this domain in those receptors bearing the domain have revealed its importance in certain instances in connection with various functions such as dimerization, activation and interaction with different coregulators (Patel and Skafar, 2015). 
HNF4 $\alpha$ (Hepatocyte Nuclear Factor 4 alpha) (also referred to as NR2A1) is a transcription factor of the nuclear receptor family that was initially identified as a regulator of liver-specific gene expression (Costa et al., 1989; Sladek et al., 1990). Since its initial discovery in the liver, HNF4 $\alpha$ has also been detected in the kidneys, pancreas, stomach, small intestine and colon (Tanaka et al., 2006). HNF4 $\alpha$ is crucial for the development and maintenance of hepatocyte function, including lipid homeostasis, transport and metabolism, as well as the detoxification of xenobiotics (Hayhurst et al., 2001; Wortham et al., 2007; Yin et al., 2011). Additional functions for HNF4 $\alpha$ in the gut and pancreas have also emerged (Drewes et al., 1996; Eeckhoute et al., 2003; Wang et al., 2000). In contrast to other types of NR, HNF4 $\alpha$ is constitutively localized in the nucleus and does not require binding of a ligand in order to homodimerize and interact with the response elements of its target genes (Yuan et al., 2009). $\mathrm{HNF} 4 \alpha$ has long been considered an orphan nuclear receptor, although crystallography of the LBD initially revealed the presence of fatty acids of various compositions bound at the level of the ligand binding pocket of HNF4 $\alpha$ (Dhe-Paganon et al., 2002). Subsequent studies have identified linoleic acid, a long chain polyunsaturated fatty acid (C18: 206), as the molecule preferentially binding to its LBD (Yuan et al., 2009); however, this binding is reversible and does not modulate the transcriptional activity of HNF4 $\alpha$. The nature of the HNF4 $\alpha$ ligand therefore remains controversial, since linoleic acid is endogenously present and does not appear necessary for receptor activity, unlike the typical mode of action of NR requiring binding to their ligand. HNF4 $\alpha$ recognizes DR1 sites (Direct Repeat 1), consisting of two repeated hexameric half-sites separated by a nucleotide, typically an adenosine (Fang et al., 2012). HNF4 $\alpha$ also recognizes direct repeats separated by two nucleotides (DR2), but with lower specificity (Jiang and Sladek, 1997). The consensus sequence of its half-sites, AGGTCA, is shared by most nonsteroidal NR (Fang et al., 2012). HNF4 $\alpha$ is considered to be an exclusive homodimer, this form being stably found in solution and is necessary to bind DNA (Jiang et al., 1995). However, both $\operatorname{RXR} \alpha / \beta / \gamma$ and $\operatorname{RAR} \alpha$ nuclear receptors, known for their ability to form heterodimers with several NR, do not assemble into heterodimers with HNF4 $\alpha$ (Jiang et al., 1995; Lee and Privalsky, 2005).

Alternative splicing is a major source of cellular protein diversity. The estimated percentage of human gene products undergoing alternative spicing has been proposed to be as high as $95 \%$ of multiexon genes, although it is still unclear how many of these splicing variants 
are actually expressed or functional (Pan et al., 2008). However, very few of these alternative protein isoforms have well-characterized cellular functions, given that studies on these proteins have either mostly concentrated on a single isoform, or do not specify which isoform was under study, hence leading to discrepancies or contradictions in protein function (Kelemen et al., 2013). In addition, a large number of alternatively spliced transcripts studied for protein-protein interaction by yeast two-hybrid assay were shown to display significant differences between reference and alternative isoforms, with many alternative isoforms interacting with different protein partners (Yang et al., 2016). These differences in protein complexes underline the importance of considering each protein isoform in order to understand its unique role(s).

In the present study, the transcriptional functions of the 12 annotated isoforms of HNF4 $\alpha$ were specifically characterized (Babeu and Boudreau, 2014; Sladek and Seidel, 2001) by generating stable lines expressing each HNF4 $\alpha$ isoform in HCT 116 cells. The entire transcriptome associated with each isoform was analyzed by RNA sequencing, as well as their respective proteome by a BioID approach coupled to quantitative mass spectrometry. This analysis integrating the vast amount of transcriptomic and proteomic data enabled the identification of transcriptional regulatory mechanisms specific to each isoform, demonstrating the importance of considering all isoforms which can exhibit distinct functions.

\section{RESULTS}

\section{New classification of $\mathrm{HNF} 4 \alpha$ isoforms}

An important issue arising from the existence of the HNF4 $\alpha$ isoforms is the lack of detail and uniformity in their descriptions in the literature and databases. Indeed, the main protein databases such as RefSeq (O'Leary et al., 2016), Uniprot (UniProt, 2019) and Ensembl (Zerbino et al., 2018) use different numbering and identification strategies for protein isoforms, and studies on proteins in the literature often do not specify which isoform is under consideration (Supplementary Table 1). Since the initial identification of HNF4 $\alpha$ in the liver, a total of 12 $\mathrm{HNF} 4 \alpha$ isoforms have been reported or predicted in the literature encompassing protein isoforms with distinct N- and C-termini regions (Babeu and Boudreau, 2014; Huang et al., 2009; Sladek and Seidel, 2001). A first classification of the different isoforms separates the different proteins depending on promoter usage (termed P1 and P2, (Boj et al., 2001; Thomas et al., 2001)) 
generating differences in the N-terminus which will include either exon 3 (isoforms $\alpha 1-3$ ) or exon 4 (isoforms $\alpha 4-6$ ) for isoforms transcribed from the P1 promoter, or exon 1 (isoforms $\alpha 7$ 9) or exon 2 (isoforms $\alpha 10-12$ ) for isoforms transcribed from the P2 promoter (Figure 1). Interestingly, only the $\mathrm{N}$-termini from isoforms $\alpha 1-3$ include the activation function 1 domain (AF-1 domain), whereas it has not been identified in the the other isoforms. In addition, alternative splicing regulation in exons 11, 12 and 13 yields another level of complexity, resulting in three different $\mathrm{C}$-termini combinations within the $\mathrm{F}$ domain, constituting the highly variable C-terminal region typical of NR.

Different numbering and identifiers are currently used when referring to the HNF4 $\alpha$ isoforms (Supplementary Table 1), and several studies on HNF4 $\alpha$ either do not precisely indicate which isoform was used, do not provide the cDNA sequence, or simply refer to a previous study. This has led to contradictory functions being attributed to HNF4 $\alpha$ as a consequence of studying different isoforms (Babeu et al., 2018; Chellappa et al., 2016; Vuong et al., 2015). In order to simplify the nomenclature of the isoforms, we now propose to follow the P1 and P2 classification of isoforms, first by sorting the isoforms from the N-termini, and then by the different C-termini as also suggested by (Ko et al., 2019). This leads to four main classes of isoforms (P1a, P1b, P2a, P2b) (Figure 1), and maintains the order of the different C-termini in order to remain consistent with the nomenclature used in most previous studies. The isoforms a (P1a and P2a) represents the canonical HNF4 $\alpha$ isoforms, whereas the isoforms b (P1b and P2b) are isoforms that have been less studied, or that have not been detected. In order to be consistent with the order of the $\mathrm{C}$-terminal between the different isoforms, we also propose to inverse the nomemclature of the $\alpha 4$ and $\alpha 5$ isoforms (Drewes et al., 1996).

\section{Expression of HNF4a isoforms in different tissues}

While multiple HNF4 $\alpha$ isoforms have been considered in several studies, the expression of some of these isoforms has only been limited to a single study ( $\alpha 5$ (Drewes et al., 1996), $\alpha 10$, $\alpha 11$ and $\alpha 12$ (Huang et al., 2009)), with $\alpha 4$ and $\alpha 6$ isoforms remaining putative, their expression having never been demonstrated. The expression of the different classes of HNF4 $\alpha$ isoforms is tightly regulated depending to the spatial context and stage of development (Chen et al., 1994). Immunohistochemical analysis of several human tissues reveals a variable distribution of P1 and 
P2 isoform expression (Tanaka et al., 2006). The intestine is the only adult organ expressing both the P1 and P2 isoforms. The expression levels of these isoform classes have been modulated in the colon, notably by RNA interference in a colorectal cancer line or by exon exchange in the mouse, in order to analyze the functional differences between P1 and P2. These studies revealed significant disparities, with P1 isoforms being involved in the regulation of cell differentiation and metabolism, whereas P2 isoforms were associated with cell proliferation and cancer progression (Babeu et al., 2018; Chellappa et al., 2016).

To validate the existence of these 12 isoforms, different tissues of the human gastrointestinal tract were selected in the present study. A human cDNA library from healthy individuals was used to study isoform expression by semi-quantitative PCR (Figure 2), and the PCR products were sequenced to confirm the exact nature of the isoform. Seven isoforms were identified in these tissues (Figure 2). The canonical isoforms of HNF4 $\alpha$ (P1: $\alpha 1, \alpha 2$, and $\alpha 3$; P2: $\alpha 7, \alpha 8$, and $\alpha 9$ ) were detected in the liver, stomach as well as all segments of the small intestine and colon. No isoforms were found in the esophagus, a tissue previously reported not to express HNF4 $\alpha$ (Tanaka et al., 2006). Although the above approach was non-quantitative, a predominance of P1 isoforms in the liver was observed, consistent with the literature (TorresPadilla et al., 2001). HNF4 $\alpha 5$ was the only non-canonical isoform identified in this experiment, and found exclusively in the liver.

Given that the expression of P1 and P2 HNF4 $\alpha$ isoforms is known to be modulated in various cancer types (Tanaka et al., 2006), various human cancer lines were hence selected in an attempt to investigate the expression of additional isoforms. Two cell lines of pancreatic origin, AsPC-1 and Capan-2, were also included into this assay given that the pancreas is a well-known organ for expressing HNF4 $\alpha$. Expression of the 12 isoforms was measured in these cell lines by semi-quantitative RT-PCR (Supplementary Figure 1), and confirmed by sequencing of the PCR products. In the context of the cell lines selected for this assay, HNF4 $\alpha 1, \alpha 2, \alpha 3, \alpha 7, \alpha 8$, and $\alpha 9$ were detected according to a pattern similar to the expression in the corresponding healthy human tissues.

\section{Generation of stable cell lines expressing inducible HNF4 $\alpha$ with GFP and BioID2}

Colorectal cancer cell lines that show endogenous expression of HNF4 $\alpha$ unequivocally express several isoforms in a concomitant manner (Supplementary Figure 1). In order to study 
the specific functions of the different HNF4 $\alpha$ isoforms, the latter had to be expressed in a cell line lacking endogenous expression of HNF4 $\alpha$. The HCT 116 cell line was ultimately selected for this purpose, since the $H N F 4 A$ gene is mutated in this line, leading to loss of its expression (Barretina et al., 2012) (Supplementary Figure 1). The Flp-In T-REx system was used to generate stable lines in HCT 116 cells for each of the HNF4 $\alpha$ isoforms, with either a GFP or a BioID2-3myc fusion protein at their C-terminal end (Figure 3A). This system allows integration of a gene at a single and known location within the genome, under the control of a doxycyclineinducible CMV promoter. In addition, this strategy supports gene expression levels that are much closer to an endogenous expression level comparatively to other transfection approaches, with these levels remaining relatively similar between the different stable cell lines.

The inducible expression of HNF4 $\alpha$ was confirmed by both immunoblotting (Figure $3 \mathrm{~B}$ ) and immunofluorescence microscopy when comparing cells incubated or not with doxycycline (Figure 3C). A similar nuclear localization was observed for all 12 isoforms, whether HNF4 $\alpha$ was fused to a GFP (Supplementary Figure 2) or to BioID2-3myc protein tag (Supplementary Figure 3). Given the single integration site, the overall expression of HNF4 $\alpha$ was expected to be relatively similar. However, differences in protein expression were observed when comparing immunoblot analysis of whole cell lysates (Supplementary Figure 4). This difference was most likely due to post-translational stability, since no correlative pattern of transcript expression was observed when measured by qPCR (Supplementary Figure 5).

\section{HNF4a isoforms have different DNA binding capacities}

Following confirmation of the expression and localization of the $12 \mathrm{HNF} 4 \alpha$ isoforms, a first functional validation was performed by measuring their ability to bind the known consensus DNA binding sequence DR1 (Fang et al., 2012; Jiang and Sladek, 1997). Electrophoretic mobility shift assays (EMSA) were carried out to determine whether the 12 isoforms could bind this consensus DNA sequence (Figure 4A). Isoform binding to a probe containing the HNF4 $\alpha$ DR1 response element resulted in a major complex shift for all isoforms except the $\alpha 4, \alpha 5$ and $\alpha 6$ isoforms (Figure 4A). Inclusion of an antibody against GFP in the binding reaction was able to supershift this complex demonstrating that the latter indeed consisted of the HNF4 $\alpha$ isoforms fused to GFP. A probe featuring a mutated DR1 sequence was used to demonstrate the specificity of interaction of the isoforms with the consensus DR1 sequence (Figure 4A). This test 
demonstrates for the first time that the $\alpha 4, \alpha 5$ and $\alpha 6$ isoforms are unable to bind DNA in the same manner as other HNF4 $\alpha$ isoforms, despite the fact that they share the same DNA binding domain. These results therefore suggest that the A/B domain from exon 4 of these isoforms can negatively regulate their DNA binding capacity, since this domain is the only common sequence for $\alpha 4, \alpha 5$ and $\alpha 6$ that is absent from the other nine HNF4 $\alpha$ isoforms.

$\mathrm{HNF} 4 \alpha$ is known to transactivate the expression of a multitude of genes, the majority of which are involved in cell differentiation, metabolism and transport of nutrients. The expression levels of four selected genes known to be upregulated by HNF4 $\alpha$ (APOA1, CREB3L3, HNF1A and VILI) and involved in several of these functions were measured by qPCR following the induction of expression of each isoform in stable HCT 116 lines (HNF4 $\alpha$ (1-12)-GFP) (Figure 4B). Significant differences in the transactivation of these genes were observed between isoforms. Although the isoform transactivation profiles were similar from one gene to another, there were a few notable exceptions. The $\alpha 1$ and $\alpha 2$ isoforms (canonical P1) were the strongest transcription inducers of the four genes tested, whereas the $\alpha 3$ isoform positively regulated CREB3L3 and VIL1 at lower levels, but not APOA1 and HNF1A (Figure 4B), thus demonstrating specificity in the regulated genes between the different isoforms. The $\alpha 4, \alpha 5$ and $\alpha 6$ isoforms showed no effect on the genes tested, suggesting that the absence of binding to the DR1 element by these isoforms has a major impact on their transactivation activity (Figure 4A). The canonical $(\alpha 7, \alpha 8)$ and non-canonical $(\alpha 10, \alpha 11)$ P2 isoforms exhibited a much lower transactivation capacity than the $\alpha 1$ and $\alpha 2$ isoforms. Of particular note, for all analyzed genes, the variants of each subgroup sharing a shorter $\mathrm{F}$ domain $(\alpha 3, \alpha 6, \alpha 9$ and $\alpha 12)$ all showed a strongly reduced or non-existent transactivation capacity for these genes. Importantly, while the isoforms exhibit differences in HNF4 $\alpha$ protein expression (as demonstrated in Supplementary Figure 5), the results presented in Figure 4B show that these variations in protein expression are not necessarily consistent with the transcriptional levels of target genes.

\section{Transcriptomics analysis of HNF4a isoforms}

In order to further study the transcriptional functions of the $12 \mathrm{HNF} 4 \alpha$ isoforms, the transcriptome of HCT $116 \mathrm{HNF} 4 \alpha$ (1-12) -GFP lines were analyzed by RNAseq. To achieve this, RNA from these lines were sequenced in triplicate, and compared to the parental cell line lacking $\mathrm{HNF} 4 \alpha$ expression. The readings were aligned to the human transcriptome constructed from the 
annotations of the RefSeq database (Supplementary Table 1). The differential expression of transcripts and genes was obtained by comparing the specific data for each isoform to the transcriptome of the control condition (HCT 116 Flp-In T-REx).

Principal component analysis (PCA) of the datasets was performed to determine the variance found between the transcripts quantified for all isoforms as well as to validate the reproducibility of the triplicates for each experiment. This analysis confirmed the propinquity of each triplicate, with the exception of the first replica for the $\alpha 3$ isoform (symbolized by A3N1) (Figure 5A). The divergence of this replica is likely explained by a weaker expression of the HNF4 $\alpha 3$ isoform in the sample (405 counts against 832 and 771 in the other two replicas). The subsequent analyses were therefore carried out by excluding this sample, and using the average value of the counts between the different biological replicas. The control condition is annotated as A0, and is located on the left and center of the PC1 and PC2 components respectively. From these analyses, the $\alpha 1$ and $\alpha 2$ isoforms caused the most variance when compared to control, while $\alpha 3$ exhibited a reduced effect. In contrast, the $\alpha 4, \alpha 5$ and $\alpha 6$ isoforms caused very little divergence. The P2 isoforms displayed an intermediate effect with respect to these two subgroups of P1 isoforms. Of note, the isoforms generally appeared to cluster strongly according to their A / B domain, with the exception of a larger divergence observed between the $\alpha 10, \alpha 11$ and $\alpha 12$ isoforms, indicating that the majority of the functional differences between the HNF4 $\alpha$ isoforms were associated with this domain rather than with the F domain. Notwithstanding the latter, a shorter $\mathrm{F}$ domain effect contained in the $\alpha 3, \alpha 6, \alpha 9, \alpha 12$ isoforms resulted in closer proximity to the negative control than to the other two isoforms containing the same A / B domain.

Gene quantification analysis revealed that the annotation contained $\sim 45000$ genes, with 18000 detected in at least one sample (using a minimal quantification of 1 TPM). To further analyze the observed variance, only those genes positively or negatively modulated by at least two-fold compared to the control, and with a minimum Benjamini-corrected p-value of 0.001, were considered. The results are viewed globally in Figure 5C as circles whose respective sizes are proportional to the number of significantly modulated genes. Positive and negative modulation levels are also presented as volcano plot representations of the sorted results in order to visualize the distribution of the genes found across the different data sets (Supplementary Figure 6). The most striking difference between the transcriptome profiles induced by the 12 
HNF4alpha isoforms was the total number of modulated genes (Figure 5C). The $\alpha 1$ and $\alpha 2$ isoforms were by far the isoforms with the greatest impact on the transcriptome in this setting. The $\alpha 4, \alpha 5$ and $\alpha 6$ isoforms conversely displayed an extremely weak effect on gene expression, consistent with the absence of DNA binding to the DR1 consensus sequence. This observation also suggests that they do not bind to a different response element with functional impact on the transcriptome. An intermediate effect was noted for the canonical and non-canonical P2 isoforms. In general, HNF4 $\alpha$ was found to be more involved in the activation of gene expression than in their repression. The genes modulated by the $\alpha 1$ and $\alpha 2$ isoforms, which are the most important regulators in this setting, were mostly modulated upward $(67 \%$ and $63 \%$, respectively). Certain isoforms such as $\alpha 9$ were mainly responsible for repression of transcription (57\%), while others such as $\alpha 3$ had an even stronger activating effect (76\%), but with a much less overall number of genes regulated (Figure 5C). Comparison of the overlap of upregulated or downregulated genes between the different isoforms showed the largest group being regulated by $\alpha 1$ and $\alpha 2$ isoforms (293 genes), although a large number of genes were also specific to $\alpha 1$ (202 genes) (Figure 5D). Of note, most of the genes regulated by the $\mathrm{P} 2$ isoforms were common to all isoforms in this group and were also regulated by at least one P1 isoform, whereas the few genes regulated by the $\alpha 4-5-6$ isoforms were completely different from the remaining isoforms (Figure 5D). Overall, these data demonstrate major differences in transcriptional function between the 12 isoforms of $\mathrm{HNF} 4 \alpha$.

\section{HNF4a isoforms have distinct interaction networks, mostly comprised of transcription factors and transcriptional coregulators}

The functional activity of $\mathrm{HNF} 4 \alpha$ is regulated by two characteristics related to its structure. Its DBD mediates the recognition of specific regulatory sequences at its target genes, while different transactivation domains promote the interaction with multiple transcriptional coregulators. Since the 12 isoforms have the same DBD, the differences in the number of modulated genes observed between the $\mathrm{HNF} 4 \alpha$ isoforms likely arise from a variable interaction of the isoforms with transcriptional coregulators via the transactivating $\mathrm{A} / \mathrm{B}$ or $\mathrm{F}$ domains. In order to determine the specific protein-protein interaction networks involving each of the HNF4 $\alpha$ isoforms, a BioID approach coupled to SILAC (Stable isotope labeling with amino acids in cell culture)-based quantitative mass spectrometry was used (Figure 6A) (Varnaite and MacNeill, 
2016). Stable HCT116 cell lines were generated from constructs expressing each of the 12 HNF4 $\alpha$ isoforms in fusion with BioID2 (Kim et al., 2016). Three conditions were thus compared using SILAC, namely the control cell line in light medium (R0K0), a cell line expressing a P1 isoform in the intermediate SILAC medium (R6K4) and a line expressing a P2 isoform in heavy medium (R10K8) (Figure 6A). The biotin-labeled protein extracts from these three conditions were then mixed in a ratio of 1: 1: 1 . The biotinylated proteins were digested with trypsin, and the resulting peptides analyzed by mass spectrometry. Quantification of the identified proteins for each isoform was performed by measuring the enrichment in comparison to the control condition (Figure 6A).

Over a thousand proteins were identified for each isoform. Enrichment ratios obtained for each quantified protein were compared between isoforms and their triplicates via a Spearman correlation. These correlations were then plotted against a color scale for easier visualization (Figure 6B). This initial analysis validated the reproducibility of the obtained results, yielding a very strong correlation between the triplicates $(0.72$ to 0.95$)$. In addition, this representation highlighted certain differences between the proteomes associated with each isoform. The lists of potential interactants for the $\alpha 4, \alpha 5$ and $\alpha 6$ isoforms were the most dissimilar compared to the other isoforms. Overall, it appeared that most of the identified proteins were similarly enriched for the 12 isoforms. Following this validation, the remaining analyses were carried out based on the average enrichment ratios obtained through the triplicates. Given the differential isoform expressions observed (Supplementary Figure 4), the enrichment ratios were normalized relative to the median.

In order to determine the type of proteins enriched by the BioID approach, enrichment analyses of GO annotations were carried out using the Panther 13.1 software. A minimum enrichment threshold of 2 was used for these assays, reducing the number of proteins to approximately 200 interactants for each isoform. Annotations of biological processes (GO-BP) regulated by these proteins showed an enrichment in the regulation of transcription, notably through histone modification and chromatin remodeling (Figure 6C). As expected, the proteins associated with these enriched biological processes were annotated with molecular functions (GO-MF) for transcription factors and transcriptional coregulators (Figure 6C). There were, however, no significant differences between the proteomes of the 12 isoforms that could be 
identified by this type of analysis, demonstrating that all of these isoforms interact with proteins with known functions in transcription.

\section{Identification of isoform-specific interaction partners of $\mathrm{HNF4a}$}

In order to determine whether specific interactors could be identified for each isoform, the respective effects of the A / B domain and F domain were decoupled. Four different A / B domains and three $\mathrm{F}$ domains are found among all isoforms. By pooling the identified proteins for all of the isoforms having one of these domains in common, this analysis enabled to provide clues as to the identification of proteins that can interact specifically with certain HNF4 $\alpha$ domains generated by alternative splicing.

The Venn diagrams presented in Figure 7 illustrate the results of this comparative analysis, which used a minimum enrichment threshold of 2. Overall, most of the identified proteins were once again enriched equally between the $12 \mathrm{HNF} 4 \alpha$ isoforms, which included 69 proteins that were enriched by a 2-fold ratio for all isoforms, in all triplicates. Among these, there were several coregulators and transcription factors known to interact with HNF4 $\alpha$, such as CBP (Dell and Hadzopoulou-Cladaras, 1999), NCOA-1 and NCOA-2 (Martinez-Jimenez et al., 2006), NCOR2 (Ruse et al., 2002) and FOSL1 (FRA-1, (Vuong et al., 2015)). This analysis, however, highlighted certain proteins that appeared to interact specifically with subgroups of isoforms that had a common A/B domain or $\mathrm{F}$ domain. Most of these proteins have never been shown to specifically interact with $\mathrm{HNF} 4 \alpha$, although their functions in transcriptional regulation strongly support this possibility. These include members of ATP-dependent chromatin remodeling complexes (BRD9 - SWI / SNF, VPS72 - NuA4, SRCAP), enzymes associated with histone modification (SIRT1, SIN3B, KDM2A, KANSL1), and members of the Mediator and PIC complexes (MED26, MED27, TAF4B). Comparison of proteins interacting with the different HNF4 $\alpha$ F domains also demonstrated specific interactions with the three different Cterminal domains (Figure 7B), including the transcriptional corepressors IRF-2BP1 and IRF2BP2.

To confirm some of these interactions, co-transfections between these newly identified FLAG-tagged interactants and GFP-tagged HNF4 $\alpha$ isoforms showing the highest SILAC enrichment ratio were performed. Following immunoprecipitation against GFP, immunoblotting against FLAG led to the validation of the interactions involving five proteins, namely 
GATAD2B $(\alpha 11), \operatorname{HNF} 4 \gamma(\alpha 4)$, IRF2BP2 $(\alpha 2)$, MTA1 $(\alpha 11)$ and ZNF629 $(\alpha 11)$ (Supplementary Figure 7). The control condition, which only expressed the FLAG construct, confirmed the specificity of interaction between $\mathrm{HNF} 4 \alpha$ and these proteins. Thus, the identification of interactions by BioID coupled to SILAC quantification provided novel information with regard to the transcription factor interaction networks of $\mathrm{HNF} 4 \alpha$.

\section{DISCUSSION}

HNF4A has been reported to produce several isoforms through the use of two different promoters and various alternative splicing events (Babeu and Boudreau, 2014). Two major groups of isoforms were classified as $\mathrm{P} 1$ - and $\mathrm{P} 2-\mathrm{HNF} 4 \alpha$, according to the usage of their specific promoter. Given the presence of four different $\mathrm{N}$ - terminal regions, we have proposed a novel nomenclature based on these differences. Although we were successful in detecting seven of the twelve possible HNF4A isoform transcripts among specific gastrointestinal tissues and cell lines, we cannot exclude that the remaining isoforms are specifically produced in other tissues or in a timely manner during development. Despite several of these transcripts being shown to produce proteins (Tanaka et al., 2006), the repetitive and combinatorial nature of $\mathrm{A} / \mathrm{B}$ and $\mathrm{F}$ domains in certain isoforms makes it impossible to detect single protein isoforms. However, the generation herein of a cellular system with controlled expression for each recombinant single isoform led to the demonstration that each isoform produces protein with possible differing post-translational stability as previously reported for subclasses of P1 isoforms (Chellappa et al., 2016). Since functional differences in the cell transcriptome were identified among each HNF4 $\alpha$ isoform, our study supports the importance for the design of thorough analyses to measure the biological impact of each single isoform in a specific cellular and developmental context.

Although all HNF4 $\alpha$ isoforms share the same DBD, our data support that P1B isoforms $(\alpha 4, \alpha 5$ and $\alpha 6$ ) do not functionally interact with DNA or influence gene expression when expressed as single isoforms producing homodimers. Our BioID approach coupled to quantitative mass spectrometry identified several transcriptional co-regulators interacting with these isoforms similarly to other HNF4 $\alpha$ isoforms. Since the common difference between these three isoforms resides in their A/B domain, we speculate that this region could interfere with DNA binding and down-modulate the transcriptional influence of $\mathrm{P} 1 \mathrm{~B}$ isoforms on gene transcription. Of note, 
similar observations were made for two RAR-related orphan alpha (ROR $\alpha$ ) nuclear receptor isoforms where $\mathrm{ROR} \alpha 1$ was shown to strongly activate transcription while ROR $\alpha 2$ interaction with RORE elements was more restricted with the result of weaker transcriptional activity (Giguere et al., 1994). Similarly to HNF4 $\alpha-\mathrm{P} 1 \mathrm{~A}$ and B isoforms, ROR $\alpha 2$ and 1 differ in their A/B domain. Whether the HNF4 $\alpha-\mathrm{P} 1 \mathrm{~B}$ subclass of isoforms act as dominant negative regulators for other HNF4 $\alpha$ isoforms in a given cellular condition will require further investigation.

HNF4 $\alpha$ was initially considered to be an exclusive homodimer, (Jiang et al., 1995). However, recent evidence demonstrate that HNF4 $\alpha$ can also form heterodimers, with distinct gene targets from the corresponding homodimers (Ko et al., 2019), and several tissues and cell lines express more than one isoform (Figure 2, Supplementary Figure 1 and (Ko et al., 2019)). The overexpression of different homodimers and heterodimers appears to regulate differentially a subset of previously reported genes, as well as inflammatory genes, underlining the importance of further studies that will tackle the complete transcriptome regulated by different combinations of HNF $4 \alpha$ isoforms.

The BioID quantitative mass spectrometry performed for each HNF4 $\alpha$ isoform identified a prominent number of common proteins that constitute ATP-dependent chromatin remodeling complexes such as the BRG1/BRM-associated factor (BAF) and the nucleosome remodeling and deacetylase (NuRD) complex (Supplementary Figure 8). These observations suggest that all $\mathrm{HNF} 4 \alpha$ isoforms have the potential to act on chromatin structure via these specific interactions. Our results also suggest that the $\mathrm{A} / \mathrm{B}$ domain is the major determinant of the differential transcriptional function of the different isoforms. However, we also observed differences in protein interactions such as IRF-2BP2. This protein was initially shown to be a corepressor of the IRF-2 transcription factor, and more recently for other transcription factors such as p53 and NFAT (Carneiro et al., 2011; Childs and Goodbourn, 2003; Koeppel et al., 2009). The BioID approach used herein show that isoforms that have the short form of the $\mathrm{F}$ repressor domain do not interact with this coregulator. Taking into account the differential interaction profile of IRF2BP2 with the HNF4 $\alpha$ isoforms, we have identified transcriptome variations that can be explained by these preferential interactions. Accordingly, our results show that the proportion of down-modulated genes was similar between the $\alpha 1$ and $\alpha 2$ isoforms (33\% and 37\%, 
respectively). This proportion fell to $24 \%$ at the level of the $\alpha 3$ isoform, with a total of approximately 8 times less negatively modulated genes. Since the IRF-2BP2 corepressor was shown to specifically interact with $\alpha 1$ and $\alpha 2$ isoforms relative to $\alpha 3$, it is possible that IRF-2BP2 may be responsible for part of this variation in the negative transcriptional regulatory function of these isoforms.

In conclusion, the present study provides an exhaustive analysis of the transcriptional cointeracting complexes and transcriptomic impact of each single $\mathrm{HNF} 4 \alpha$ isoforms in a specific cellular setting. Given that specificity of biological functions was previously attributed to HNF4 $\alpha$-P1 and -P2 subclasses (Babeu et al., 2018; Chellappa et al., 2016), this work provides a strong rationale to further detail the exact nature of contributing $\mathrm{HNF} 4 \alpha$ isoforms in given biological systems and to design innovative strategies in exploring the specific biological functions that may be coincidental to the expression of these specific isoforms in the biological field. Similar analyses could be designed for the study of other human NR isoforms that result from similar alternative promoter and splicing events.

\section{EXPERIMENTAL MODEL AND SUBJECT DETAILS}

All cell lines were obtained from the ATCC. HCT 116 (human colorectal cancer (hCRC)), Caco2/15 (hCRC), Capan-2 (human pancreatic adenoma), HepG2 (human hepatocellular carcinoma) and 293T (transformed human embryonic kidney) cell lines were cultured in DMEM. AsPC-1 (human pancreatic adenocarcinoma), COLO 205 (hCRC) and DLD-1 (hCRC) cell lines were cultured in RPMI. The T84 (hCRC) cell line was cultured in DMEM/F-12. The LoVo (hCRC) cell line was cultured in F-12K. The HT-29 (hCRC) cell line was cultured in McCoy's 5A. All cultured media were supplemented with $10 \%$ FBS and cell lines were grown in a humidified incubator at $37^{\circ} \mathrm{C}$ with $5 \% \mathrm{CO}_{2}$. The Human Digestive System MTC Panel cDNA library was purchased from Clontech Laboratories (Mountain View, USA). The cDNA preparations found in this library are derived from the combination of cDNAs from several healthy Caucasian individuals between 18 and 61 years of age, and were provided at a concentration of $1.0 \mathrm{ng} / \mu \mathrm{l}$ following first-strand cDNA preparation for each tissue. A total of 12 tissues of the digestive 
system were included in the bank: liver, stomach, esophagus, duodenum, jejunum, ileum, ileum, cecum, ascending, transverse and descending colon, as well as the rectum.

\section{METHOD DETAILS}

\section{Total RNA isolation and Reverse Transcription}

Total RNA of HCT 116, Caco-2/15, T84, COLO 205, LoVo, DLD-1, HT-29, HepG2, AsPC-1, Capan-2 and HCT 116 HNF4 $\alpha$ (1-12) -GFP cell lines was isolated using RNeasy RNA isolation kit (QIAGEN). The stable HCT $116 \mathrm{HNF} 4 \alpha$ (1-12) -GFP cell lines were induced for 48 hours with $2.5 \mu \mathrm{g} / \mathrm{ml}$ doxycycline (Clontech Laboratories, Mountain View, USA) prior to extraction of total RNAs. cDNA synthesis was performed with the SuperScript IV-RT reverse transcriptase enzyme (Thermo Fisher Scientific, Waltham, USA). Two $\mu$ g of RNA were added in a total volume of $10 \mu \mathrm{l}$ by supplementing with DEPC water. A mixture containing $2.4 \mu \mathrm{l}$ of $0.5 \mu \mathrm{g} / \mu \mathrm{l}$ poly (dT) oligos (Amersham Biosciences, Little Chalfont, United Kingdom) and $0.8 \mu$ of 25 mM dNTPs (Amersham Biosciences, Little Chalfont, United Kingdom) was added to the RNA, then heated for 5 minutes at $75^{\circ} \mathrm{C}$ and placed on ice for an additional 5 minutes. A $10 \mu$ volume of RT reaction mixture, described in Table 4, was added to the RNA. The reaction was incubated for 1 hour at $50^{\circ} \mathrm{C}$, before inactivating the SuperScript IV-RT by heating for 5 minutes at $95^{\circ} \mathrm{C}$. The cDNA samples were subsequently stored at $-20^{\circ} \mathrm{C}$.

\section{Expression of isoforms in different human cancer cell lines}

Oligonucleotides specific for each isoform and the reference genes were obtained from Integrated DNA Technologies (IDT, San Jose, USA) (Supplementary Table 6). The cDNA from HCT 116 HNF4 $\alpha$ (1-12) -GFP lines was used as a positive control for each isoform. Expression levels of the HPRT and PUM1 genes were used as references, with an amplification of 26 cycles at a hybridization temperature of $60^{\circ} \mathrm{C}$ and an elongation time of 20 seconds.

\section{Expression of isoforms in the different tissues of the human digestive system}

The expression of the $12 \mathrm{HNF} 4 \alpha$ isoforms in the different human gastrointestinal tract tissues was assessed by PCR. The primers specific to each HNF4 $\alpha$ isoform (Supplementary Table 6) were used to assess the expression of the isoforms by PCR in each of the aforementioned listed 
tissues. The reagents used for the amplification were the same as described previously, the template DNA being in this instance a volume of $3.7 \mu \mathrm{l}$ of cDNA. The PCR reactions were performed according to the PCR conditions detailed in the previous section, for a first round of 30 cycles. A $10 \mu \mathrm{l}$ aliquot of the reaction was retrieved, and the remainder of the reaction was supplemented again at $20 \mu \mathrm{l}$ at the initial reaction concentrations for a second round of PCR of 6 additional cycles. The expression levels of the POLR2A and PSMB2 genes were used as references, with an amplification of 26 cycles. A PCR product corresponding to each isoform was sequenced to ensure the specificity of the amplification. Plasmid pUC19 was digested with the SmaI restriction enzyme (New England Biolabs, Ipswich, USA) in CutSmart buffer (New England Biolabs, Ipswich, USA) for 1 hour at $25^{\circ} \mathrm{C}$, and subsequently purified on gel agarose. Ligation between the PCR product and the digested pUC19 plasmid was carried out in a 20:1 ratio (insert: vector) with T4 DNA ligase (New England Biolabs, Ipswich, USA) for 3 hours at room temperature. Sequencing was performed via the Genome Sequencing and Genotyping Platform (Université Laval, Quebec, Canada).

\section{Cloning of HNF4a isoforms}

The $12 \mathrm{HNF} 4 \alpha$ isoforms were cloned into the donor vector pENTR11 (Thermo Fisher Scientific, Waltham, USA) in three distinct steps consisting in initially cloning the sequence common to the 12 isoforms, inserting the different $\mathrm{N}$-terminal termini (A/B domains) on each side, followed by the different C-termini (F domain). The Gateway system (Invitrogen, Carlsbad, USA) was subsequently used to obtain constructs allowing the expression of isoforms in fusion with the GFP and BioID2 protein labels.

\section{Cloning of the common sequence in pENTR11}

The common sequence to the 12 isoforms was amplified by PCR from the pLentiHNF4 $\alpha 2$-GFP plasmid. This plasmid contains the $\alpha 2$ isoform of HNF4 $\alpha$ (NM_000457.3) synthesized by Feldan Inc. and cloned into pLenti6/V5 (Invitrogen). The amplified common sequence measures 1014 base pairs, covering 71-86\% of the complete sequence of the different $\mathrm{HNF} 4 \alpha$ isoforms, and contains the C, D and E domains of HNF4 $\alpha$. Oligonucleotides used for amplification (Supplementary Table 6) were obtained from Integrated DNA Technologies (IDT, San Jose, USA). These enabled the addition of SpeI and SfoI restriction sites within the common sequence, at the 5 'and 3 ' ends, respectively, without changing the amino acid composition of the 
$\mathrm{HNF} 4 \alpha$ protein. In parallel, these primers also allowed the upstream and downstream addition of the sequence of SalI and XhoI restriction sites, in consecutive order. The amplification reaction was performed with iProof High-Fidelity DNA Polymerase enzyme (Bio-Rad, Hercules, USA) according to the manufacturer's recommendations. The reactions were performed in the T100 thermal cycler (Bio-Rad, Hercules, USA).

The PCR product was purified on agarose gel using the EZ-10 Spin Column DNA Gel Extraction Kit (Bio Basic, Markham, Canada). The purified PCR product and the pENTR11 plasmid were digested with SalI and XhoI restriction enzymes (New England Biolabs, Ipswich, USA) in NEBuffer 3.1 digest buffer (New England Biolabs, Ipswich, USA) for 2 hours at $37^{\circ} \mathrm{C}$, then purified on agarose gel. The digested and purified pENTR11 plasmid was then dephosphorylated by the Antarctic Phosphatase enzyme (New England Biolabs, Ipswich, USA) for 30 minutes at $37^{\circ} \mathrm{C}$, before ligation between the PCR product and pENTR11 in a 5: 1 ratio (insert: vector) with T4 DNA ligase (New England Biolabs, Ipswich, USA) for 2 hours at room temperature. The pENTR11- (common sequence of HNF4 $\alpha$ ) plasmid was sequenced via the Genome Sequencing and Genotyping Platform (Laval University, Quebec, Canada).

\section{Inserting the $\mathrm{N}$-Termini into pENTR11}

The four different N-terminal ends of the HNF4 $\alpha$ isoforms, surrounded by SalI (5 ') and SpeI (3') restriction sites, were obtained from Integrated DNA Technologies (IDT, San Jose, USA). The sequences corresponding to the N-terminal ends of the $\alpha 1 / 2 / 3$ and $\alpha 4 / 5 / 6$ isoform groups were synthesized directly in the form of double-stranded DNA (gBlocks Gene Fragments). The sequences corresponding to the $\mathrm{N}$-terminal ends of the $\alpha 7 / 8 / 9$ and $\alpha 10 / 11 / 12$ isoform groups were obtained in the form of single-stranded oligonucleotides. In order to obtain a doublestranded sequence, the sense and antisense oligonucleotides were mixed at a concentration of 1 $\mu \mathrm{M}$ in a $5 \mathrm{mM} \mathrm{NaCl}$ buffer, $20 \mathrm{mM}$ Tris $\mathrm{pH} 7.5$. Hybridization of the oligonucleotides was performed by placing the reaction mixture in a heated dry bath set at $98^{\circ} \mathrm{C}$ for 2 minutes and subsequently allowing the reaction to return to room temperature after turning off the bath. The pENTR11- (common HNF4 $\alpha$ sequence) plasmid as well as the four N-termini were digested with SalI and SpeI restriction enzymes (New England Biolabs, Ipswich, USA) in CutSmart buffer (New England Biolabs, Ipswich), USA) for 2 hours at $37^{\circ} \mathrm{C}$, before being purified on agarose gel. A ligation reaction with a 10: 1 ratio (insert: vector) with T4 DNA ligase for 2 hours at room temperature was then performed to insert each $\mathrm{N}$-terminus upstream of the common sequence of 
$\mathrm{HNF} 4 \alpha$ already present in pENTR11. The four different plasmids thus obtained were sequenced via the Genome Sequencing and Genotyping Platform (Laval University, Quebec, Canada).

\section{Inserting the C-Termini into pENTR11}

The three different C-terminal ends of the HNF4 $\alpha$ isoforms, lined with a 3 'XhoI restriction site, were synthesized directly as double-stranded DNA (gBlocks Gene Fragments) (IDT, San Jose, USA). These three sequences as well as the four pENTR11 plasmids containing the different $\mathrm{N}$-terminal ends in front of the common $\mathrm{HNF} 4 \alpha$ sequence were digested by the restriction enzymes SfoI (only for the plasmids) and XhoI (New England Biolabs, Ipswich, USA) in the CutSmart buffer for 2 hours at $37^{\circ} \mathrm{C}$, then gel purified. A ligation reaction as described previously was subsequently performed to insert each C-terminus downstream of the common HNF4 $\alpha$ sequence into pENTR11. The pairing of three C-terminal ends at the four Ntermini clones previously cloned hence generated 12 pENTR11-HNF4 $\alpha$ plasmids (1-12), containing the complete sequence of each of the $12 \mathrm{HNF} 4 \alpha$ isoforms. These plasmids were sequenced via the Genome Sequencing and Genotyping Platform (Laval University, Quebec, Canada).

\section{Generation of pcDNA-DEST47, pgLAP5.2-GFP and pgLAP5.2-BioID2-3myc}

The sequences of the 12 isoforms cloned into the pENTR11 vector were transferred into the pcDNA-DEST47 expression vectors (Thermo Fisher Scientific, Waltham, USA), pgLAP5.2 (a gift from Peter Jackson (Addgene plasmid \#19706)) and pgLAP5.2-BioID2-3Xmyc by Gateway cloning, via an LR reaction according to the manufacturer's instructions (Thermo Fisher Scientific, Waltham, USA). The pcDNA-DEST47-HNF4 $\alpha$ (1-12), pgLAP5.2-HNF4 $\alpha$ (112) and pgLAP5.2-HNF4 $\alpha$ (1-12) -BioID2-3Xmyc plasmids were sequenced via the Genome Sequencing and Genotyping Platform (Laval University, Quebec, Canada). The control empty pGLAP5.2-BioID2-3Xmyc- plasmid was cloned in order to express the BioID2-3Xmyc protein label alone as a control for mass spectrometry experiments. To achieve the latter, the pGLAP5.2BioID2-3Xmyc plasmid was amplified by PCR so as to remove an approximately $1.8 \mathrm{~kb}$ fragment containing the chloramphenicol resistance gene and the ccdB gene.

\section{Generation of inducible stable cell lines}

The stable cell lines HCT 116 HNF4 $\alpha$ (1-12) -GFP, HCT 116 HNF4 $\alpha$ (1-12) BioID2-3Xmyc and HCT 116 BioID2-3Xmyc-control were generated using the Flp-In T-REx system (Thermo Fisher 
Scientific, Waltham, USA) using the pgLAP5.2-HNF4 $\alpha$ (1-12), pgLAP5.2-HNF4 $\alpha$ (1-12) BioID2-3Xmyc and pGLAP5.2-BioID2-3Xmyc-empty plasmids, respectively.

Transfections for stable lines were performed with HCT 116 Flp-In T-Rex cells, upon reaching approximately $70 \%$ confluence, in a $60 \mathrm{~mm}$ Petri dish using Lipofectamine LTX (Thermo Fisher Scientific, Waltham, USA) as a transfection agent. A total of $500 \mathrm{ng}$ of plasmid DNA was mixed with $4.5 \mu \mathrm{g}$ of the Flp-Recombinase expression vector pOG44 (Thermo Fisher Scientific, Waltham, USA), $5 \mu$ of Plus Reagent (Thermo Fisher Scientific, Waltham, USA) and OptiMEM medium (Thermo Fisher Scientific, Waltham, USA) to complete the reaction at a final volume of $300 \mu \mathrm{l}$. A second mixture was prepared simultaneously containing $8 \mu \mathrm{l}$ of lipofectamine LTX and $292 \mu \mathrm{l}$ of Opti MEM medium. These two reactions were incubated for 5 minutes at room temperature before being mixed and incubated for 30 minutes at room temperature. Meanwhile, HCT 116 cells were washed once with 1X PBS followed by the addition of $2 \mathrm{ml}$ of DMEM culture medium (Thermo Fisher Scientific, Waltham, USA) containing 10\% FBS (Wisent, St. John the Baptist, Canada). The selection was started 24 hours later, by adding the antibiotics blasticidine $\mathrm{S}(5 \mu \mathrm{g} / \mathrm{ml})$ and hygromycin B (100 $\mu \mathrm{g} / \mathrm{ml})$. The clonal population was maintained over time by the sustained use of these antibiotics, and the induction of constructs was achieved via the addition of $2.5 \mu \mathrm{g} / \mathrm{ml}$ doxycycline (Clontech Laboratories, Mountain View, USA) in the medium at the desired moment.

\section{EMSA}

Oligonucleotides containing the HNF4 $\alpha$ consensus DR1 response element (DR1 WT) or a mutated sequence (DR1 MUT) labeled with a biotin molecule at the 5 'end (Table 6), were obtained from Integrated DNA Technologies (IDT, San Jose, USA). Hybridized probes were diluted to a concentration of $20 \mathrm{nM}$ for binding reactions. Nuclear extracts were isolated from $293 \mathrm{~T}$ cell lines transfected with the different pcDNA-DEST47-HNF4 $\alpha$ (1-12) plasmids. The cells, cultured at an approximate $90 \%$ confluence in $60 \mathrm{~mm}$ Petri dishes, were trypsinized and subsequently centrifuged at $1500 \mathrm{x}$ g for 5 minutes. The cell pellet was washed twice with $1 \mathrm{ml}$ of 1X PBS, followed by centrifugation after each wash. The cells were then resuspended in $1 \mathrm{ml}$ of nuclear extraction buffer A (10 mM HEPES pH 7.9, $10 \mathrm{mM} \mathrm{KCl,} 1.5 \mathrm{mM} \mathrm{MgCl} 2,0.34 \mathrm{M}$ sucrose, $10 \%$ glycerol, $1 \mathrm{mM}$ DTT, and EDTA-free Protease Inhibitor Cocktail (Roche Applied Science, Penzberg, Germany)). A volume of $10 \mu \mathrm{l}$ of $10 \%$ Triton X-100 solution was added to the cell suspension to obtain a final concentration of $0.1 \%$ Triton X-100. The cells were lysed in 
this buffer for 8 minutes on ice, so as to only rupture the plasma membrane while maintaining the integrity of the nuclear membrane. The cells were centrifuged at $1300 \mathrm{x} \mathrm{g}$ for 5 minutes at $4^{\circ} \mathrm{C}$. The supernatant, corresponding to the cytoplasmic protein fraction, was collected and stored at $-80^{\circ} \mathrm{C}$. The nuclei-containing pellets were next resuspended in $150 \mu \mathrm{l}$ of nuclear extraction buffer B (1\% Triton X-100, $150 \mathrm{mM} \mathrm{NaCl,} 20 \mathrm{mM}$ Tris $\mathrm{pH}$ 7.4, $1 \mathrm{mM}$ DTT, and cOmplete EDTA-free Protease Inhibitor Cocktail). The nuclear fraction was incubated with stirring for 30 to 60 minutes at $4{ }^{\circ} \mathrm{C}$, before being stored at $-80{ }^{\circ} \mathrm{C}$. The nuclear and cytoplasmic fractions were centrifuged at 20,000 x g for 15 minutes to eliminate cell debris. These fractions were assayed using the Pierce BCA Protein Assay kit (Thermo Fisher Scientific, Waltham, USA) as recommended by the manufacturer. Immunoblots of the HNF4 $\alpha$, histone H3 and GAPDH proteins were performed in order to validate the quality of the nuclear extraction.

The binding reactions were prepared in several incubation steps at room temperature, in a final volume of $20 \mu \mathrm{l}$. A first incubation of 10 minutes was carried out by mixing $6 \mu \mathrm{l}$ of nuclear extracts $(6 \mu \mathrm{g}), 2 \mu \mathrm{l}$ of 10X binding buffer (100 mM Tris pH 7.5, $10 \mathrm{mM}$ EDTA, $1 \mathrm{M} \mathrm{KCl,} \mathrm{50 \%}$ glycerol and $1 \mathrm{mM}$ DTT) and $1 \mu \mathrm{l}$ poly [d (IC)] (1 $\mu \mathrm{g} / \mu \mathrm{l})$ (cat. \# 10108812001, Roche Applied Science, Penzberg, Germany). The biotinylated probe was then added to the mixture at a final concentration of $1 \mathrm{nM}$ and incubated for 25 minutes. Supershift was performed by adding $1.5 \mu \mathrm{l}$ of purified GFP monoclonal antibody $(0.4 \mu \mathrm{g} / \mu \mathrm{l})$ (cat. \# 11814460001, Roche Applied Science, Penzberg, Germany) for an additional incubation period of 15 minutes. A $2 \mu$ volume of $6 X-$ EMSA loading buffer (6X TBE, 30\% glycerol, $0.125 \%$ bromophenol blue) was subsequently added to the reaction mixture prior to loading on a non-denaturing polyacrylamide gel.

The non-denaturing polyacrylamide gels were prepared using the SureCast Gel HandCast System (Invitrogen, Carlsbad, USA), in a "mini gel" format $(8 \times 8 \times 0.1 \mathrm{~cm})$ at a concentration of $4 \%$ acrylamide: bis, $10 \%$ glycerol and TBE $0.5 \mathrm{X}$ (45 $\mu \mathrm{M}$ Tris, $45 \mu \mathrm{M}$ boric acid, $1 \mathrm{mM}$ EDTA $\mathrm{pH}$ 8.0). A 60-min pre-migration at $100 \mathrm{~V}$ was performed using cold $0.5 \mathrm{X}$ TBE buffer as migration buffer. The samples were then loaded onto the gel and migrated at $100 \mathrm{~V}$ for 100 minutes. Binding reactions were transferred onto a positively-charged nylon membrane Amersham Hybond-N + (cat \#RPN203B, GE Healthcare Life Sciences, Marlborough, USA). The blot was performed in $0.5 \mathrm{X}$ TBE buffer at $200 \mathrm{~mA}$ for 90 minutes at $4^{\circ} \mathrm{C}$. Membrane crosslinking was subsequently achieved using a UV Stratalinker 2400 (Stratagene, San Diego, 
USA), equipped with UV light bulbs (254 nm, 5 x $15 \mathrm{~W})$. The auto-crosslink function was used, equivalent to an emitted energy of $1200 \mu \mathrm{J}$ (x 100) for 45 seconds.

The steps leading to detection of the probe on the positively-charged nylon membrane were performed using the Chemiluminescent Nucleic Acid Detection Module (Thermo Fisher Scientific, Waltham, USA). Detection of biotinylated probes was performed using the ChemiDoc MP imaging system (Bio-Rad, Hercules, USA) and Amersham Hyperfilm ECL autoradiographic films (GE Healthcare Life Sciences, Marlborough, USA).

\section{Quantitative real-time PCR}

The transactivation of different HNF4 $\alpha$ target genes by its isoforms was analyzed by realtime quantitative PCR (RT-qPCR), using LightCycler 96 (Roche Applied Science, Penzberg, Germany) and cDNA from 48hr-induced HCT 116 HNF4 $\alpha$ (1-12) -GFP lines. The oligonucleotides used for the amplification of the tested genes were obtained from Integrated DNA Technologies (IDT, San Jose, USA) (Supplementary Table 7). The reactions were performed with the SYBR Green Master Fast Start reaction mixture (Roche Applied Science, Penzberg, Germany) as recommended by the manufacturer. Analysis of the amplification and melting curves was performed using LightCycler 96 software version 1.1.0.1320 (Roche Applied Science, Penzberg, Germany). The relative expression of the genes was calculated by comparison with the TBP reference gene with the formula $\mathrm{E}_{\text {target }}\left(\mathrm{Cp}_{\text {Control- }}-\mathrm{Cp}_{\text {Sample }}\right) X \mathrm{E}_{\text {reference }}$ $\left(\mathrm{Cp}_{\text {Sample }}-\mathrm{Cp}_{\text {Control }}\right)$.

\section{Transcriptomics}

\section{Preparation of total RNA}

The HCT 116 HNF4 $\alpha$ (1-12) -GFP and HCT 116 Flp-In T-Rex lines were inoculated in $60 \mathrm{~mm}$ Petri dishes and incubated for 48 hours in the presence of $2.5 \mu \mathrm{g} / \mathrm{ml}$ doxycycline. Total RNA of these 13 lines was extracted into triplicates using RNeasy RNA isolation kit (QIAGEN). The concentration as well as the quality of the RNAs was evaluated first by NanoDrop (Thermo Fisher Scientific, Waltham, United States) via the RNomics platform of the Université de Sherbrooke and by a 2100 Bioanalyzer (Agilent, Santa Clara, USA). The samples were then sent to McGill University's Innovation Center and Génome Québec.

\section{Preparation of libraries and sequencing}

Libraries were generated from $250 \mathrm{ng}$ of total RNA. Enrichment of the mRNA was performed using the NEBNext Poly (A) Magnetic Insulation Module (New England Biolabs, 
Ipswich, USA). The cDNA synthesis was performed via the use of NEBNext RNA First Strand Synthesis and NEBNext Ultra Directional RNA Second Strand Synthesis modules (New England Biolabs, Ipswich, USA). The final steps for the preparation of the libraries were carried out using the NEBNext Ultra II DNA Library Prep Kit for Illumina (New England Biolabs, Ipswich, USA). PCR adapters and primers were obtained from New England Biolabs. The libraries were quantified using Quant-iTT PicoGreen® dsDNA Assay Kit (Thermo Fisher Scientific, Waltham, USA) and Kapa Illumina GA with Revised Primers-SYBR Universal Fast Kit (Kapa Biosystems, Wilmington, USA). The average size of the RNA fragments was determined using the LabChip GX instrument (PerkinElmer, Waltham, USA). Sequencing of the libraries was performed using NovaSeq 6000 (Illumina, San Diego, USA) using a S2 PE100 protocol.

\section{Sequence alignment}

The quality of the sequencing results was visualized using the FastQC 0.11.5 tool (Wingett and Andrews, 2018). The sorting of the data according to their quality score was performed using the Trimmomatic 0.36 software (Bolger et al., 2014). The transcriptome used for the alignment of the reads was constructed from the human genome GRCh38.p12 and annotations from RefSeq (NCBI Homo sapiens Annotation Release 109) (O'Leary et al., 2016). Transcriptome alignment and quantification were performed using the Kallisto 0.44.0 tool (Bray et al., 2016). Results from Kallisto counts were used to quantify transcripts, as well as genes by addition of transcripts. The DESeq2 1.14.1 software was used to calculate the differential expression of transcripts and genes for each isoform in comparison with the control sample (Love et al., 2014).

\section{Mass spectrometry}

\section{Cell culture and induction of different constructions}

The stable HCT 116 HNF4 $\alpha$ (1-12) -BioID2-3Xmyc and HCT 116 BioID2-3Xmyccontrol cell lines were cultured in three different SILAC media designated as light (R0K0), medium (R6K4) and heavy (R10K8). SILAC media contained DMEM + 4.5 g/L glucose, Lglutamine, sodium pyruvate (Thermo Fisher Scientific, Waltham, USA) supplemented with 10\% of triple-dialyzed FBS (Thermo Fisher Scientific, Waltham, USA), $10 \mathrm{mM}$ HEPES, $2 \mathrm{mM}$ GlutaMAX, $100 \mathrm{U} / \mathrm{ml}$ penicillin and $100 \mu \mathrm{g} / \mathrm{ml}$ streptomycin. To these media were added different L-arginine and L-lysine isotopes at final concentrations of $42 \mu \mathrm{g} / \mathrm{ml}$ and $63.5 \mu \mathrm{g} / \mathrm{ml}$ respectively to obtain light, medium and heavy media. The light medium contained L-arginine 
R0 (Sigma-Aldrich A6969, St. Louis, USA) and L-lysine K0 (Sigma Aldrich A8662, St. Louis, USA). The medium medium contained L-arginine R6 (Cambridge Isotope Laboratories, Inc. CLM-2265, Tewksbury, USA) and L-lysine K4 (Cambridge Isotope Laboratories, Inc. DLM2640, Tewksbury, USA). The heavy medium contained L-arginine R10 (Cambridge Isotope Laboratories, Inc. CNLM-539, Tewksbury, USA) and L-lysine K8 (Cambridge Isotope Laboratories, Inc. CNLM-291, Tewksbury, USA). The different SILAC culture media were then filtered on a Stericup filtration unit (EMD Millipore, Burlington, USA) prior to use. The HCT 116 BioID2-3Xmyc cells, serving as a control condition for the mass spectrometry experiments, were cultured in the light medium. The HCT $116 \mathrm{HNF} 4 \alpha$ (1-6) -BioID2-3Xmyc lines were cultured in the medium medium while the HCT $116 \mathrm{HNF} 4 \alpha$ (7-12) -BioID2-3Xmyc lines were cultured in the heavy medium. Culture in SILAC medium involved a minimum of 5 passages at a ratio of 1:4 followed by incubation for 2-3 days in polystyrene Petri dishes 100 or $150 \mathrm{~mm}$, at $37^{\circ} \mathrm{C}$ in a controlled atmosphere at $5 \% \mathrm{CO} 2$.

A $150 \mathrm{~mm}$ Petri dish was used for each condition. During the last passage in SILAC medium, doxycycline (Clontech Laboratories, Mountain View, USA) was added to the cells at a concentration of $2.5 \mu \mathrm{g} / \mathrm{ml} 48$ hours before the streptavidin pulldown experiment, when the cells were at a confluence of 40 to $50 \%$. The next day, 24 hours prior to the pulldown, biotin (SigmaAldrich, St. Louis, USA) was added to the cells at a final concentration of $50 \mu \mathrm{M}$. The cells were then washed three times with $1 \mathrm{X}$ PBS, trypsinized and centrifuged at $1500 \mathrm{x} \mathrm{g}$ for 5 minutes at $4^{\circ} \mathrm{C}$. The cell pellets were washed again twice with $1 \times$ PBS.

\section{Immunoprecipitation of biotinylated proteins}

The cell pellets were lysed in $1 \mathrm{ml}$ of RIPA buffer $(50 \mathrm{mM}$ Tris-HCl, $\mathrm{pH} 7.5,150 \mathrm{mM}$ $\mathrm{NaCl}, 1.5 \mathrm{mM} \mathrm{MgCl}$ 2, 0.1\% SDS, 1\% IGEPAL CA-630 (Sigma-Aldrich , St. Louis, USA)), 1 mM PMSF, 0.4\% sodium deoxycholate, $1 \mathrm{mM}$ DTT, and the EDTA-free Protease Inhibitor Cocktail inhibitor per $150 \mathrm{~mm}$. The cell lysates were rotated for 20 to 30 minutes at $4^{\circ} \mathrm{C}$ and sonicated on ice with a Sonic Dismembrator Model 120 (Thermo Fisher Scientific, Waltham, USA) at $30 \%$ amplitude three times for 10 to 15 seconds interspaced by 5 -sec pauses. A $40 \mu \mathrm{l}$ aliquot of each sample was taken for assay using the Pierce BCA Protein Assay kit (Thermo Fisher Scientific, Waltham, USA). The samples were then rotated for an additional hour at $4^{\circ} \mathrm{C}$, after the addition of $10 \mu \mathrm{l}$ of $0.1 \mathrm{M}$ EGTA (1 mM final). A combination of the three SILAC conditions (light, medium and heavy) was performed prior to the pulldown by mixing $3.5 \mathrm{mg}$ of 
total extract of each condition and supplementing to a volume of $3 \mathrm{ml}$ with RIPA buffer. A $45 \mu \mathrm{l}$ aliquot of $20 \%$ SDS was added to each sample (0.4\% final). The samples were rotated for 15 minutes at $4^{\circ} \mathrm{C}$ and subsequently centrifuged at $20,000 \mathrm{x}$ g for 20 minutes at $4^{\circ} \mathrm{C}$.

High performance streptavidin Sepharose beads (GE Healthcare Life Sciences, Marlborough, USA) were used for the pulldown at $50 \mu$ per combined sample. The beads were washed three times with $1 \mathrm{ml}$ of RIPA buffer containing $0.4 \%$ SDS. Washings were performed by rotating the beads for 5 minutes at $4^{\circ} \mathrm{C}$ and subsequently centrifuging at $6000 \mathrm{x}$ for 3 minutes at $4^{\circ} \mathrm{C}$ before removing the supernatant. The washed beads were resuspended at $50 \%$ concentration in the same buffer and added to the samples in $5 \mathrm{ml}$ tubes. The samples were rotated for 3 hours at $4^{\circ} \mathrm{C}$. The beads were centrifuged at $6000 \mathrm{x}$ g for 3 minutes at $4^{\circ} \mathrm{C}$, and a $100 \mu \mathrm{l}$ aliquot of the supernatant was removed. The beads were transferred to Low Binding microtubes (Sarstedt, Nümbrecht, Germany) and washed according to the parameters described above. A first wash was performed with $1.5 \mathrm{ml}$ of BioID wash buffer (2\% SDS, $50 \mathrm{mM}$ Tris-HCl, $\mathrm{pH} 7.5$ ), followed by three washes with $1 \mathrm{ml}$ of RIPA buffer containing 0.4\% SDS and five washes with $1 \mathrm{ml}$ of $20 \mathrm{mM}$ ammonium bicarbonate buffer. An aliquot corresponding to $5 \%$ of the total amount of beads was collected. The final washed beads were stored at $-80^{\circ} \mathrm{C}$, as were all the aliquots collected during the experiment.

\section{Reduction, alkylation and digestion of proteins}

All buffers used in this stage were prepared with MS-grade water. The protein reduction step was carried out by incubating the beads in $100 \mu \mathrm{l}$ of $20 \mathrm{mM}$ ammonium bicarbonate buffer containing $10 \mathrm{mM}$ DTT (Thermo Fisher Scientific, Waltham, USA) with stirring (1250 rpm) for 30 minutes at $60^{\circ} \mathrm{C}$. The alkylation of the proteins was carried out by adding another $100 \mu \mathrm{l}$ of $20 \mathrm{mM}$ ammonium bicarbonate buffer, and then supplementing with $15 \mathrm{mM}$ iodoacetamide (Sigma-Aldrich, Saint-Louis, United States) final before stirring for 1 hour at room temperature away from light. The IAA was then neutralized by completing with $15 \mathrm{mM}$ DTT and stirring for 10 minutes at $37^{\circ} \mathrm{C}$. The proteins were digested by adding $1 \mu \mathrm{g}$ Pierce MS-grade trypsin (Thermo Fisher Scientific, Waltham, USA) and incubated overnight at $37^{\circ} \mathrm{C}$ with shaking.

\section{Purification and desalting of the peptides on C18 columns}

Digestion was stopped by adding $1 \%$ formic acid (FA) (Thermo Fisher Scientific, Waltham, USA) to a total volume of $200 \mu \mathrm{l}$, followed by stirring for 5 minutes at room temperature. The beads were spun at $6000 \mathrm{x}$ g for 3 minutes before harvesting the supernatant 
and transferring to a new low binding microtube. The beads were resuspended in $200 \mu$ l of buffer containing 60\% acetonitrile (ACN) (Sigma-Aldrich, St. Louis, USA) and 0.1\% FA, and subsequently stirred for 5 minutes at room temperature. The supernatant was harvested and combined with that obtained previously. These samples were thereafter concentrated by a centrifugal evaporator at $65^{\circ} \mathrm{C}$ until complete drying (approximately 2 hours), and resuspended in $30 \mu \mathrm{l}$ of $0.1 \%$ trifluoroacetic acid (TFA) buffer (Sigma-Aldrich, St. Louis, USA). The peptides were purified with ZipTip 10- $\mu \mathrm{l}$ micropipette tips containing a C18 column (EMD Millipore, Burlington, USA). The ZipTip was first moistened by suctioning $10 \mu \mathrm{l}$ of $100 \%$ ACN solution three times, then equilibrated by suctioning $10 \mu \mathrm{l}$ of $0.1 \%$ TFA buffer three times. Each peptide sample was passed on the balanced ZipTip by 10 succeeding up-and-downs of $10 \mu \mathrm{l}$ of the sample. This step was performed three times in order to pass the entire sample on the column. The ZipTip was then washed with $10 \mu \mathrm{l}$ of $0.1 \%$ TFA buffer three times. The elution of the peptides was performed in a new low-binding microtube, 10 times with a volume of $10 \mu \mathrm{l}$ of $50 \% \mathrm{ACN}$ and $0.1 \%$ FA buffer. This step was carried out three times to obtain a final volume of $30 \mu \mathrm{l}$. The peptides were then concentrated by centrifugal evaporator at $65^{\circ} \mathrm{C}$ until complete drying (approximately 30 minutes) and then resuspended in $25 \mu \mathrm{l}$ of $1 \%$ FA buffer. Peptides were assayed using a NanoDrop spectrophotometer (Thermo Fisher Scientific, Waltham, USA) and read at an absorbance of $205 \mathrm{~nm}$. The peptides were then transferred to a glass vial (Thermo Fisher Scientific, Waltham, USA) and stored at $-20^{\circ} \mathrm{C}$ until analysis by mass spectrometry.

\section{LC-MS/MS analysis}

Trypsin-digested peptides were separated using a Dionex Ultimate 3000 nanoHPLC system. Ten $\mu \mathrm{l}$ of sample (a total of $2 \mu \mathrm{g}$ ) in $1 \%$ ( $\mathrm{vol} / \mathrm{vol}$ ) formic acid were loaded with a constant flow of $4 \mu \mathrm{l} / \mathrm{min}$ onto an Acclaim PepMap100 C18 column (0.3 mm id x $5 \mathrm{~mm}$, Dionex Corporation). After trap enrichment, peptides were eluted onto an EasySpray PepMap C18 nano column (75 $\mu \mathrm{m}$ x $50 \mathrm{~cm}$, Dionex Corporation) with a linear gradient of 5-35\% solvent B (90\% acetonitrile with $0.1 \%$ formic acid) over 240 minutes with a constant flow of $200 \mathrm{nl} / \mathrm{min}$. The HPLC system was coupled to an OrbiTrap QExactive mass spectrometer (Thermo Fisher Scientific Inc) via an EasySpray source. The spray voltage was set to $2.0 \mathrm{kV}$ and the temperature of the column set to $40^{\circ} \mathrm{C}$. Full scan MS survey spectra (m/z 350-1600) in profile mode were acquired in the Orbitrap with a resolution of 70,000 after accumulation of 1,000,000 ions. The ten most intense peptide ions from the preview scan in the Orbitrap were fragmented by 
collision-induced dissociation (normalized collision energy 35\% and resolution of 17,500) after the accumulation of 50,000 ions. Maximal filling times were $250 \mathrm{~ms}$ for the full scans and $60 \mathrm{~ms}$ for the MS/MS scans. Precursor ion charge state screening was enabled and all unassigned charge states as well as singly, 7 and 8 charged species were rejected. The dynamic exclusion list was restricted to a maximum of 500 entries with a maximum retention period of 40 seconds and a relative mass window of $10 \mathrm{ppm}$. The lock mass option was enabled for survey scans to improve mass accuracy. Data were acquired using the Xcalibur software.

\section{Protein identification by MaxQuant analysis}

The raw files were analyzed using the MaxQuant version 1.6.2.2 software (Cox and Mann, 2008) and the Uniprot human database (16/07/2013). Isoform analyses were initially performed separately in order to obtain enrichment ratios for the complete sequence of each isoform. A common analysis was then performed to integrate all raw MS/MS analysis files. The MaxQuant software default settings were used, except for the following parameters: multiplicity of 3 SILAC media (R0K0, R6K4 and R10K8), identification values "PSM FDR", "Protein FDR" and "Site decoy fraction" 0.05, minimum ratio count of 1 and selection of the "Re-quantify" option. Following the analysis, the results were sorted according to several parameters. Proteins positive for at least one of the "Reverse", "Only.identified.by.site" and "Potential.contaminant" categories were eliminated, as well as proteins identified from a single peptide. The ratios identified in only one of the three replicas for each experiment were eliminated. The ratios identified in two of the three replicas were eliminated when they were considered to be too divergent, i.e. when the standard deviation was greater than the average of the two enrichment ratios. Outliers for the ratios measured in the three replicas were detected using the Grubbs test at a value of $\alpha=0.05$ and then eliminated. Following this sorting, proteins for which no ratio was calculated in at least one experiment were removed. Gene ontology enrichment analyses were performed using the Panther 13.1 tool (Mi et al., 2010). Heatmap visualizations were created using the Morpheus software (https://software.broadinstitute.org/morpheus/).

\section{DATA DEPOSITION}

The HNF4 $\alpha$ RNAseq dataset was deposited to the NCBI Gene Expression Omnibus (GEO; https://www.ncbi.nlm.nih.gov/geo/) under the accession number GSE125852. 
The mass spectrometry proteomics data was deposited to the ProteomeXchange Consortium via the PRIDE (Vizcaino et al., 2016) partner repository with the dataset identifier PXD012146.

\section{SUPPLEMENTARY INFORMATION}

Supplementary Information includes eight figures and seven tables.

\section{ACKNOWLEDGEMENTS}

This work was supported by the Canadian Institutes of Health Research (CIHR) (grant number MOP-123469 to F.M.B and grant number PJT-156180 to F.B.), the Natural Sciences and Engineering Research Council of Canada (NSERC) (grant number RGPIN-2017-06096 to F.B.) and by the Cancer Research Society (to F.M.B.). F.M.B. and M.S.S. are FRQS Junior II scholars (award number 32956 to F.M.B and 34877 to M.S.). E.L. is recipient of NSERC and FRQS scholarships and J.S. is a recipient of FRQNT and NSERC scholarships. M.S.S., F.B. and F.M.B. are members of the FRQS-funded « Centre de Recherche du CHUS».

\section{AUTHOR CONTRIBUTIONS}

E.L. and J.-P.B. performed the majority of the experiments and analyzed the data. J.S. and M.S. performed the analysis of the RNAseq which includes Figure 5 and Suppl. Figure 6. D.L. provided help with the cloning, the generation of the plasmids and the mass spectrometry analysis. E.J. contributed to the EMSA, as well as the validations by co-immunoprecipitation assays. F.B. and F-M.B. contributed to the design of the experiments, supervised the project and prepared the manuscript.

\section{DECLARATION OF INTEREST}

The authors declare no competing interests. 


\section{Figure legends}

Figure 1: The HNF4A gene leads to the expression of 12 isoforms, through the use of alternative promoters and alternative splicing.

The proximal P1 promoter can produce two distinct N-terminal ends through either exon 3 (P1a) or exon 4 (P1b), and the same number of isoforms from the distal P2 promoter are possible from either exon 1 (P2a) or exon 2 (P2b). Furthermore, alternative splicing at the C-terminal end can produce an additional three isoforms for each of these subgroups, resulting in twelve possible isoforms. The $\mathrm{P} 1$ and $\mathrm{P} 2$ promoters of the $H N F 4 A$ gene are separated by approximately 46,000 bp.

Figure 2: HNF4 $\alpha$ isoforms are expressed at varying levels in different tissues of the human gastrointestinal tract.

Expression of isoforms was assessed by semi-quantitative PCR in the liver, esophagus, stomach, and in various segments of the small intestine and colon. The $\alpha 4, \alpha 6, \alpha 10, \alpha 11$ and $\alpha 12$ isoforms were not detected in any of these tissues. The POLR2A and PSMB2 genes were used as reference genes.

Figure 3: Generation of stable cell lines expressing inducible HNF4 $\alpha$ with GFP and BioID2.

A) The Flp-In T-REx system was used to generate stable lines in HCT 116 cells for each of the HNF4 $\alpha$ isoforms, with either a GFP or a BioID2-3myc fusion protein at its C-terminal. The constructs of the $12 \mathrm{HNF} 4 \alpha$ isoforms fused with the GFP or BioID2-3myc protein labels were expressed following the induction of the stable lines in the HCT 116 cells. B) Immunoblots against the GFP and myc protein labels were performed to detect the expression of the different fusion proteins following induction with doxycycline of the cell lines stably expressing HNF4 $\alpha 1$. The expression levels of the GAPDH protein in these total protein extracts were used as a reference. C) Nuclear localization of HNF4 $\alpha 1$ was confirmed by immunofluorescence to detect the GFP tag (left) or the myc tag (right).

Figure 4: HNF4a isoforms do not all recognize the DR1 consensus response element of the nuclear receptor.

A) $293 \mathrm{~T}$ cells were transfected for 24 hours with the different HNF4 $\alpha$ (1-12)-GFP constructs. Nuclear extracts from these cells were used to perform EMSA. A 5'-biotinylated DNA probe containing the normal or mutated DR1 consensus sequence of 5'-biotinylated HNF4 $\alpha$ was incubated with each cell extract and the DNA-protein complexes were resolved by nondenaturing electrophoresis. Supershifts were performed using an antibody against GFP to confirm the presence of GFP-HNF4 $\alpha$ in the observed complexes. The biotinylated probes were revealed with streptavidin-HRP. B) Known target genes of $\mathrm{HNF} 4 \alpha$ were measured by quantitative RT-PCR reactions (qPCR) performed on samples from stable HCT 116 HNF4 $\alpha$ (112)-GFP lines that were induced for 48 hours in the presence of $2.5 \mu \mathrm{g} / \mathrm{ml}$ doxycycline

Figure 5: Transcriptomics analysis of HNF4a isoforms by RNAseq. 
A) PCA analysis of the RNAseq data from GFP cell lines expressing each of the $12 \mathrm{HNF} 4 \alpha$ isoforms (A1-A12) and the control condition (A0). The biological triplicates for each sample are represented by N1/N2/N3 following the isoform number. The two main components PC1 and PC2 were used for two-dimensional visualization of the analysis. B) Hierarchical analysis of the cell lines expressing the different HNF4 $\alpha$ (1-12)-GFP were compared based on their RNA expression profiles using the $\log _{2}$ fold change. C) Representation of the number of transcripts showing significant up and down regulation for each of the HNF4 $\alpha$ isoforms. A minimum absolute modulation threshold of 2 combined with an adjusted $p$-value threshold $\leq 0.001$ was used to determine significance. The size of the circles is proportional to the total number of genes modulated for each isoform. The blue color represents the proportion of up-modulated genes relative to the control condition, while the black-colored portion represents the negatively modulated genes. D) Graphical representation with the number of regulated genes common to the different isoforms or unique to specific isoforms, with green indicating upregulation and red indicating downregulation. Only groups with more than 10 genes are shown.

\section{Figure 6: Identification of protein interactions of HNF4 $\alpha$ isoforms using the BioID approach coupled with quantitative mass spectrometry.}

A) The HCT 116 HNF4 $\alpha$ (1-12) -BioID2-3myc and the HCT 116 control line BioID2-3mycempty cell lines were cultured in SILAC medium, induced for 48 hours with doxycycline and incubated for 24 hours with biotin. The total extracts from these cells were combined equally. The biotinylated proteins were precipitated with streptavidin-coupled beads and then trypsindigested on beads. The peptides were analyzed by LC-MS/MS, before quantifying the results using MaxQuant. The experiments were performed in triplicates B) The identified interacting proteins were analyzed for gene ontology enrichment for biological processes (GO-BP, green) and molecular functions (GO-MF, purple) annotations for the proteins identified by each of the HNF4 $\alpha$ isoforms. The Panther 13.1 tool was used for the above analyses while the Morpheus software was used to visualize the results as a heatmap. A minimum enrichment ratio threshold of 2 was used. The negative value of the logarithm in base 10 of the p-value is represented according to a color scale for each annotation. C) Diagram showing the enrichment ratios according to the experimental conditions used for culture in SILAC medium. Heatmap visualization comparing the association between the protein enrichment ratios identified for each isoform according to a Spearman correlation. The data are presented according to the biological triplicates carried out for each isoform.

\section{Figure 7: Several proteins specifically interact with isoforms that have a common A / B or F domain.}

Venn diagrams comparing specifically identified proteins in certain subgroups of HNF4 $\alpha$ isoforms. A minimum enrichment ratio threshold of 2 was used. (A) Comparison of isoformspecific interactants sharing the same A/B domain. (B) Comparison of isoform-specific interactants sharing the same F domain. 


\section{Supplementary Figure Legends}

Supplementary Figure 1: HNF4 $\alpha$ isoforms are expressed at varying levels in different human cancer cell lines.

The expression of the isoforms was evaluated by semi-quantitative RT-PCR in the indicated cell lines. HPRT and PUM1 genes were used as reference genes.

\section{Supplementary Figure 2: GFP-tagged HNF4a localization by immunofluorescence microscopy.}

Cells expressing the different GFP-tagged HNF4 $\alpha$ isoforms were fixed, labeled with a GFP antibody (green) and the nuclei stained with DAPI (blue).

Supplementary Figure 3: BioID2-3myc-tagged HNF4 $\alpha$ localization by immunofluorescence microscopy.

Cells expressing the different BioID2-3myc-tagged HNF4 $\alpha$ isoforms were fixed, labeled with a myc antibody (green) and the nuclei stained with DAPI (blue).

\section{Supplementary Figure 4: Protein expression analysis of all 12 stable cell lines (GFP and BioID2) by immunoblotting.}

Protein expression from whole cell lysates of cell lines expressing each of the HNF4 $\alpha$ isoforms following induction with doxycycline was assessed by immunoblotting with a GFP antibody (A) and a myc antibody (B).

\section{Supplementary Figure 5: Relative mRNA expression of HNF4 $\alpha$ isoforms in the stable cell} lines.

Analysis of the transcript levels in each of the cell lines expressing the GFP-tagged HNF4 $\alpha$ isoforms by qPCR using oligonucleotides recognizing GFP.

Supplementary Figure 6: Volcano plots of statistical significance against fold-change comparing each HNF4 $\alpha$ isoforms with the control.

The base 10 logarithm of the adjusted p-value is presented as a function of the logarithm in base 2 of the modulation level (FoldChange). A minimum absolute modulation threshold of 2 combined with an adjusted p-value threshold $\leq 0.001$ was used. Genes above this threshold are modulated upwards (in green) or downward (in red).

Supplementary Figure 7: Validation of the interactions between the HNF4 $\alpha$ isoforms and five proteins identified by the BioID approach.

$293 \mathrm{~T}$ cells were co-transfected for 48 hours with the indicated GFP-tagged HNF4 $\alpha$ isoform and potential FLAG-tagged interaction partners (GATAD2B, HNF4 $\gamma$, IRF-2BP2, MTA1 or ZNF629). Protein complexes were immunoprecipitated using a GFP antibody from total cell 
extracts. The co-immunoprecipitations were revealed with GFP and FLAG antibodies, making it possible to validate the interaction between $\mathrm{HNF} 4 \alpha$ and the five proteins indicated above $(\mathrm{n}=2)$.

Supplementary figure 8: Chromatin remodeling complex identification through BioID-MS.

The three main complexes with the associated subunits are displayed with the average standardized SILAC enrichment scores for BAF / PBAF and NuRD complexes.

Supplementary Table 1: Identification and annotations of HNF4 $\alpha$ isoforms in RefSeq, Uniprot and Ensembl.

Supplementary Table 2: RNAseq results (gene name, intensities, fold change, p-values).

Supplementary Table 3: RNAseq quality control statistics.

Supplementary Table 4: Listing of the different SILAC label combinations.

Supplementary Table 5: Mass spectrometry data for each of the HNF4 $\alpha$ isoforms.

Supplementary Table 6: Semi-quantitative RT-PCR primers.

Supplementary Table 7: Real-time quantitative RT-PCR primers. 


\section{REFERENCES}

Babeu, J.P., and Boudreau, F. (2014). Hepatocyte nuclear factor 4-alpha involvement in liver and intestinal inflammatory networks. World J Gastroenterol 20, 22-30.

Babeu, J.P., Jones, C., Geha, S., Carrier, J.C., and Boudreau, F. (2018). P1 promoter-driven HNF4alpha isoforms are specifically repressed by beta-catenin signaling in colorectal cancer cells. J Cell Sci 131.

Barretina, J., Caponigro, G., Stransky, N., Venkatesan, K., Margolin, A.A., Kim, S., Wilson, C.J., Lehar, J., Kryukov, G.V., Sonkin, D., et al. (2012). The Cancer Cell Line Encyclopedia enables predictive modelling of anticancer drug sensitivity. Nature 483, 603-607.

Boj, S.F., Parrizas, M., Maestro, M.A., and Ferrer, J. (2001). A transcription factor regulatory circuit in differentiated pancreatic cells. Proc Natl Acad Sci U S A 98, 14481-14486.

Bolger, A.M., Lohse, M., and Usadel, B. (2014). Trimmomatic: a flexible trimmer for Illumina sequence data. Bioinformatics 30, 2114-2120.

Bray, N.L., Pimentel, H., Melsted, P., and Pachter, L. (2016). Near-optimal probabilistic RNA-seq quantification. Nat Biotechnol 34, 525-527.

Carneiro, F.R., Ramalho-Oliveira, R., Mognol, G.P., and Viola, J.P. (2011). Interferon regulatory factor 2 binding protein 2 is a new NFAT1 partner and represses its transcriptional activity. Mol Cell Biol 31, 2889-2901.

Chellappa, K., Deol, P., Evans, J.R., Vuong, L.M., Chen, G., Briancon, N., Bolotin, E., Lytle, C., Nair, M.G., and Sladek, F.M. (2016). Opposing roles of nuclear receptor HNF4alpha isoforms in colitis and colitisassociated colon cancer. Elife 5 .

Chen, W.S., Manova, K., Weinstein, D.C., Duncan, S.A., Plump, A.S., Prezioso, V.R., Bachvarova, R.F., and Darnell, J.E., Jr. (1994). Disruption of the HNF-4 gene, expressed in visceral endoderm, leads to cell death in embryonic ectoderm and impaired gastrulation of mouse embryos. Genes Dev 8, 2466-2477. Childs, K.S., and Goodbourn, S. (2003). Identification of novel co-repressor molecules for Interferon Regulatory Factor-2. Nucleic Acids Res 31, 3016-3026.

Costa, R.H., Grayson, D.R., and Darnell, J.E., Jr. (1989). Multiple hepatocyte-enriched nuclear factors function in the regulation of transthyretin and alpha 1-antitrypsin genes. Mol Cell Biol 9, 1415-1425. Cox, J., and Mann, M. (2008). MaxQuant enables high peptide identification rates, individualized p.p.b.range mass accuracies and proteome-wide protein quantification. Nat Biotechnol 26, 1367-1372. Dell, H., and Hadzopoulou-Cladaras, M. (1999). CREB-binding protein is a transcriptional coactivator for hepatocyte nuclear factor-4 and enhances apolipoprotein gene expression. J Biol Chem 274, 9013-9021. Dhe-Paganon, S., Duda, K., Iwamoto, M., Chi, Y.I., and Shoelson, S.E. (2002). Crystal structure of the HNF4 alpha ligand binding domain in complex with endogenous fatty acid ligand. J Biol Chem 277, 37973-37976.

Drewes, T., Senkel, S., Holewa, B., and Ryffel, G.U. (1996). Human hepatocyte nuclear factor 4 isoforms are encoded by distinct and differentially expressed genes. Mol Cell Biol 16, 925-931.

Eeckhoute, J., Moerman, E., Bouckenooghe, T., Lukoviak, B., Pattou, F., Formstecher, P., Kerr-Conte, J., Vandewalle, B., and Laine, B. (2003). Hepatocyte nuclear factor 4 alpha isoforms originated from the P1 promoter are expressed in human pancreatic beta-cells and exhibit stronger transcriptional potentials than P2 promoter-driven isoforms. Endocrinology 144, 1686-1694.

Fang, B., Mane-Padros, D., Bolotin, E., Jiang, T., and Sladek, F.M. (2012). Identification of a binding motif specific to HNF4 by comparative analysis of multiple nuclear receptors. Nucleic Acids Res 40, 5343-5356. Germain, P., Staels, B., Dacquet, C., Spedding, M., and Laudet, V. (2006). Overview of nomenclature of nuclear receptors. Pharmacol Rev 58, 685-704.

Giguere, V. (1999). Orphan nuclear receptors: from gene to function. Endocr Rev 20, 689-725. 
Giguere, V., Tini, M., Flock, G., Ong, E., Evans, R.M., and Otulakowski, G. (1994). Isoform-specific aminoterminal domains dictate DNA-binding properties of ROR alpha, a novel family of orphan hormone nuclear receptors. Genes Dev 8, 538-553.

Hayhurst, G.P., Lee, Y.H., Lambert, G., Ward, J.M., and Gonzalez, F.J. (2001). Hepatocyte nuclear factor 4alpha (nuclear receptor 2A1) is essential for maintenance of hepatic gene expression and lipid homeostasis. Mol Cell Biol 21, 1393-1403.

Heery, D.M., Kalkhoven, E., Hoare, S., and Parker, M.G. (1997). A signature motif in transcriptional coactivators mediates binding to nuclear receptors. Nature 387, 733-736.

Huang, J., Levitsky, L.L., and Rhoads, D.B. (2009). Novel P2 promoter-derived HNF4alpha isoforms with different $\mathrm{N}$-terminus generated by alternate exon insertion. Exp Cell Res 315, 1200-1211.

Jiang, G., Nepomuceno, L., Hopkins, K., and Sladek, F.M. (1995). Exclusive homodimerization of the orphan receptor hepatocyte nuclear factor 4 defines a new subclass of nuclear receptors. Mol Cell Biol 15, 5131-5143.

Jiang, G., and Sladek, F.M. (1997). The DNA binding domain of hepatocyte nuclear factor 4 mediates cooperative, specific binding to DNA and heterodimerization with the retinoid $\mathrm{X}$ receptor alpha. J Biol Chem 272, 1218-1225.

Kelemen, O., Convertini, P., Zhang, Z., Wen, Y., Shen, M., Falaleeva, M., and Stamm, S. (2013). Function of alternative splicing. Gene 514, 1-30.

Khorasanizadeh, S., and Rastinejad, F. (2001). Nuclear-receptor interactions on DNA-response elements. Trends Biochem Sci 26, 384-390.

Kim, D.I., Jensen, S.C., Noble, K.A., Kc, B., Roux, K.H., Motamedchaboki, K., and Roux, K.J. (2016). An improved smaller biotin ligase for BiolD proximity labeling. Mol Biol Cell 27, 1188-1196.

Ko, H.L., Zhuo, Z., and Ren, E.C. (2019). HNF4alpha Combinatorial Isoform Heterodimers Activate Distinct Gene Targets that Differ from Their Corresponding Homodimers. Cell Rep 26, 2549-2557 e2543.

Koeppel, M., van Heeringen, S.J., Smeenk, L., Navis, A.C., Janssen-Megens, E.M., and Lohrum, M. (2009). The novel p53 target gene IRF2BP2 participates in cell survival during the p53 stress response. Nucleic Acids Res 37, 322-335.

Lavery, D.N., and McEwan, I.J. (2005). Structure and function of steroid receptor AF1 transactivation domains: induction of active conformations. Biochem J 391, 449-464.

Lee, S., and Privalsky, M.L. (2005). Multiple mutations contribute to repression by the v-Erb A oncoprotein. Oncogene 24, 6737-6752.

Love, M.I., Huber, W., and Anders, S. (2014). Moderated estimation of fold change and dispersion for RNA-seq data with DESeq2. Genome Biol 15, 550.

Martinez-Jimenez, C.P., Gomez-Lechon, M.J., Castell, J.V., and Jover, R. (2006). Underexpressed coactivators PGC1alpha and SRC1 impair hepatocyte nuclear factor 4 alpha function and promote dedifferentiation in human hepatoma cells. J Biol Chem 281, 29840-29849.

Mi, H., Dong, Q., Muruganujan, A., Gaudet, P., Lewis, S., and Thomas, P.D. (2010). PANTHER version 7: improved phylogenetic trees, orthologs and collaboration with the Gene Ontology Consortium. Nucleic Acids Res 38, D204-210.

O'Leary, N.A., Wright, M.W., Brister, J.R., Ciufo, S., Haddad, D., McVeigh, R., Rajput, B., Robbertse, B., Smith-White, B., Ako-Adjei, D., et al. (2016). Reference sequence (RefSeq) database at NCBI: current status, taxonomic expansion, and functional annotation. Nucleic Acids Res 44, D733-745.

Pan, Q., Shai, O., Lee, L.J., Frey, B.J., and Blencowe, B.J. (2008). Deep surveying of alternative splicing complexity in the human transcriptome by high-throughput sequencing. Nat Genet 40, 1413-1415. Patel, S.R., and Skafar, D.F. (2015). Modulation of nuclear receptor activity by the F domain. Mol Cell Endocrinol 418 Pt 3, 298-305.

Pawlak, M., Lefebvre, P., and Staels, B. (2012). General molecular biology and architecture of nuclear receptors. Curr Top Med Chem 12, 486-504. 
Robinson-Rechavi, M., Escriva Garcia, H., and Laudet, V. (2003). The nuclear receptor superfamily. J Cell Sci 116, 585-586.

Ruse, M.D., Jr., Privalsky, M.L., and Sladek, F.M. (2002). Competitive cofactor recruitment by orphan receptor hepatocyte nuclear factor 4alpha1: modulation by the F domain. Mol Cell Biol 22, 1626-1638. Sladek, F.M., and Seidel, S.D. (2001). Hepatocyte nuclear factor $4 \alpha$. In Nuclear Receptors and Genetic Disease TP Burris and ERB McCabe, editors Academic Press, San Diego, CA, 309-361.

Sladek, F.M., Zhong, W.M., Lai, E., and Darnell, J.E., Jr. (1990). Liver-enriched transcription factor HNF-4 is a novel member of the steroid hormone receptor superfamily. Genes Dev 4, 2353-2365.

Tanaka, T., Jiang, S., Hotta, H., Takano, K., Iwanari, H., Sumi, K., Daigo, K., Ohashi, R., Sugai, M., Ikegame, C., et al. (2006). Dysregulated expression of P1 and P2 promoter-driven hepatocyte nuclear factor4alpha in the pathogenesis of human cancer. J Pathol 208, 662-672.

Thomas, H., Jaschkowitz, K., Bulman, M., Frayling, T.M., Mitchell, S.M., Roosen, S., Lingott-Frieg, A., Tack, C.J., Ellard, S., Ryffel, G.U., et al. (2001). A distant upstream promoter of the HNF-4alpha gene connects the transcription factors involved in maturity-onset diabetes of the young. Hum Mol Genet 10, 20892097.

Torres-Padilla, M.E., Fougere-Deschatrette, C., and Weiss, M.C. (2001). Expression of HNF4alpha isoforms in mouse liver development is regulated by sequential promoter usage and constitutive $3^{\prime}$ end splicing. Mech Dev 109, 183-193.

UniProt, C. (2019). UniProt: a worldwide hub of protein knowledge. Nucleic Acids Res 47, D506-D515. Varnaite, R., and MacNeill, S.A. (2016). Meet the neighbors: Mapping local protein interactomes by proximity-dependent labeling with BiolD. Proteomics 16, 2503-2518.

Vizcaino, J.A., Csordas, A., del-Toro, N., Dianes, J.A., Griss, J., Lavidas, I., Mayer, G., Perez-Riverol, Y., Reisinger, F., Ternent, T., et al. (2016). 2016 update of the PRIDE database and its related tools. Nucleic Acids Res 44, D447-456.

Vuong, L.M., Chellappa, K., Dhahbi, J.M., Deans, J.R., Fang, B., Bolotin, E., Titova, N.V., Hoverter, N.P., Spindler, S.R., Waterman, M.L., et al. (2015). Differential Effects of Hepatocyte Nuclear Factor 4 alpha Isoforms on Tumor Growth and T-Cell Factor 4/AP-1 Interactions in Human Colorectal Cancer Cells. Mol Cell Biol 35, 3471-3490.

Wang, H., Maechler, P., Antinozzi, P.A., Hagenfeldt, K.A., and Wollheim, C.B. (2000). Hepatocyte nuclear factor 4alpha regulates the expression of pancreatic beta -cell genes implicated in glucose metabolism and nutrient-induced insulin secretion. J Biol Chem 275, 35953-35959.

Wingett, S.W., and Andrews, S. (2018). FastQ Screen: A tool for multi-genome mapping and quality control. F1000Res 7, 1338.

Wortham, M., Czerwinski, M., He, L., Parkinson, A., and Wan, Y.J. (2007). Expression of constitutive androstane receptor, hepatic nuclear factor 4 alpha, and P450 oxidoreductase genes determines interindividual variability in basal expression and activity of a broad scope of xenobiotic metabolism genes in the human liver. Drug Metab Dispos 35, 1700-1710.

Yang, X., Coulombe-Huntington, J., Kang, S., Sheynkman, G.M., Hao, T., Richardson, A., Sun, S., Yang, F., Shen, Y.A., Murray, R.R., et al. (2016). Widespread Expansion of Protein Interaction Capabilities by Alternative Splicing. Cell 164, 805-817.

Yin, L., Ma, H., Ge, X., Edwards, P.A., and Zhang, Y. (2011). Hepatic hepatocyte nuclear factor 4alpha is essential for maintaining triglyceride and cholesterol homeostasis. Arterioscler Thromb Vasc Biol 31, 328-336.

Yuan, X., Ta, T.C., Lin, M., Evans, J.R., Dong, Y., Bolotin, E., Sherman, M.A., Forman, B.M., and Sladek, F.M. (2009). Identification of an endogenous ligand bound to a native orphan nuclear receptor. PLoS One 4, e5609.

Zerbino, D.R., Achuthan, P., Akanni, W., Amode, M.R., Barrell, D., Bhai, J., Billis, K., Cummins, C., Gall, A., Giron, C.G., et al. (2018). Ensembl 2018. Nucleic Acids Res 46, D754-D761. 
bioRxiv preprint doi: https://doi.org/10.1101/585604; this version posted March 21, 2019. The copyright holder for this preprint (which was not certified by peer review) is the author/funder. All rights reserved. No reuse allowed without permission.

Zhang, Z., Burch, P.E., Cooney, A.J., Lanz, R.B., Pereira, F.A., Wu, J., Gibbs, R.A., Weinstock, G., and Wheeler, D.A. (2004). Genomic analysis of the nuclear receptor family: new insights into structure, regulation, and evolution from the rat genome. Genome Res 14, 580-590. 


\section{INDEX}

\section{MAIN TEXT}

Figure 1: The HNF4A gene leads to the expression of 12 isoforms, through the use of alternative promoters and alternative splicing.

Figure 2: The isoforms of HNF4 $\alpha$ are expressed at varying levels in different tissues of the human gastrointestinal tract.

Figure 3: Generation of stable cell lines expressing inducible HNF4a with GFP and BiolD2.

Figure 4: The isoforms of HNF4a can not all recognize the DR1 consensus response element of the nuclear receptor.

Figure 5: Transcriptomics analysis of HNF4a isoforms by RNAseq.

Figure 6: Identification of protein interactions of HFH4 isoforms using the BiolD approach coupled with quantitative mass spectrometry.

Figure 7: Several proteins specifically interact with isoforms that have a common A / B or F domain.

\section{SUPPLEMENTARY DATA}

\section{Supplementary Figures}

Supplementary Figure 1: The isoforms of HNF4 $\alpha$ are expressed at varying levels in different human cancer cell lines.

Supplementary Figure 2: GFP-tagged HNF4a localization by immunofluorescence microscopy.

Supplementary Figure 3: 3X mycBioID2-tagged HNF4a localization by immunofluorescence microscopy.

Supplementary Figure 4: Protein expression analysis of all 12 stable cell lines (GFP and BioID2) by immunoblotting.

Supplementary Figure 5: Relative mRNA expression of HNF4a isoforms in the stable cell lines.

Supplementary Figure 6: Volcano plots of statistical significance against fold-change comparing each HNF4a isoforms with the control.

Supplementary Figure 7: Validation of the interactions between the isoforms of HNF4 $\alpha$ and five proteins identified by the BiolD approach.

Supplementary Figure 8: Chromatin remodeling complexes identification through BiolD-MS.

\section{Supplementary Tables}

Supplementary Table 1: Identification and annotations of HNF4a isoforms in RefSeq, Uniprot and Ensembl.

Supplementary Table 2: RNAseq results (gene name, intensities, fold change, p-values).

Supplementary Table 3: RNAseq quality control statistics.

Supplementary Table 4: Details for the different SILAC label combinations.

Supplementary Table 5: Mass spectrometry data for each of the HNF4a isoforms.

Supplementary Table 6: Semi-quantitative RT-PCR primers. 
bioRxiv preprint doi: https://doi.org/10.1101/585604; this version posted March 21, 2019. The copyright holder for this preprint (which was not certified by peer review) is the author/funder. All rights reserved. No reuse allowed without permission.

MAIN TEXT

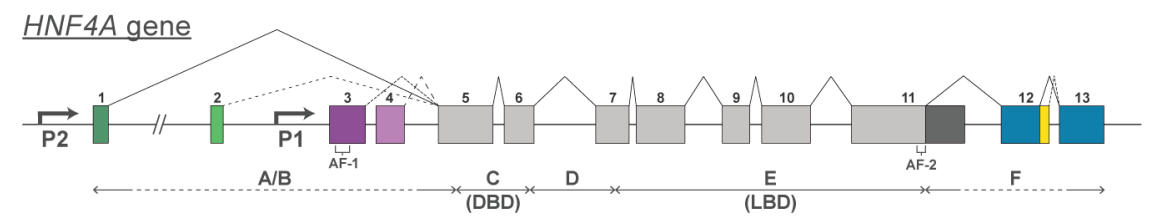

HNF4a isoforms
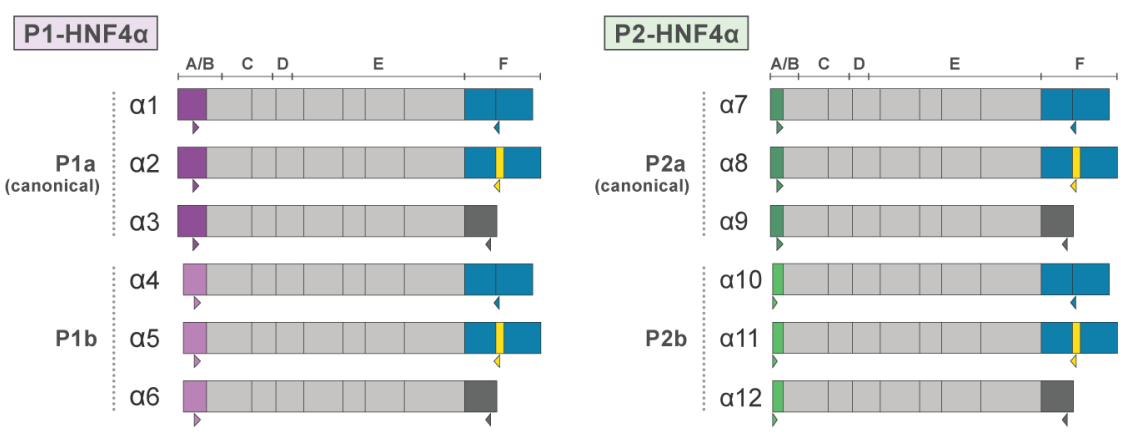

Figure 1: The HNF4A gene leads to the expression of 12 isoforms, through the use of alternative promoters and alternative splicing. (1.5 columns ; 114mm) 
bioRxiv preprint doi: https://doi.org/10.1101/585604; this version posted March 21, 2019. The copyright holder for this preprint (which was not certified by peer review) is the author/funder. All rights reserved. No reuse allowed without permission.

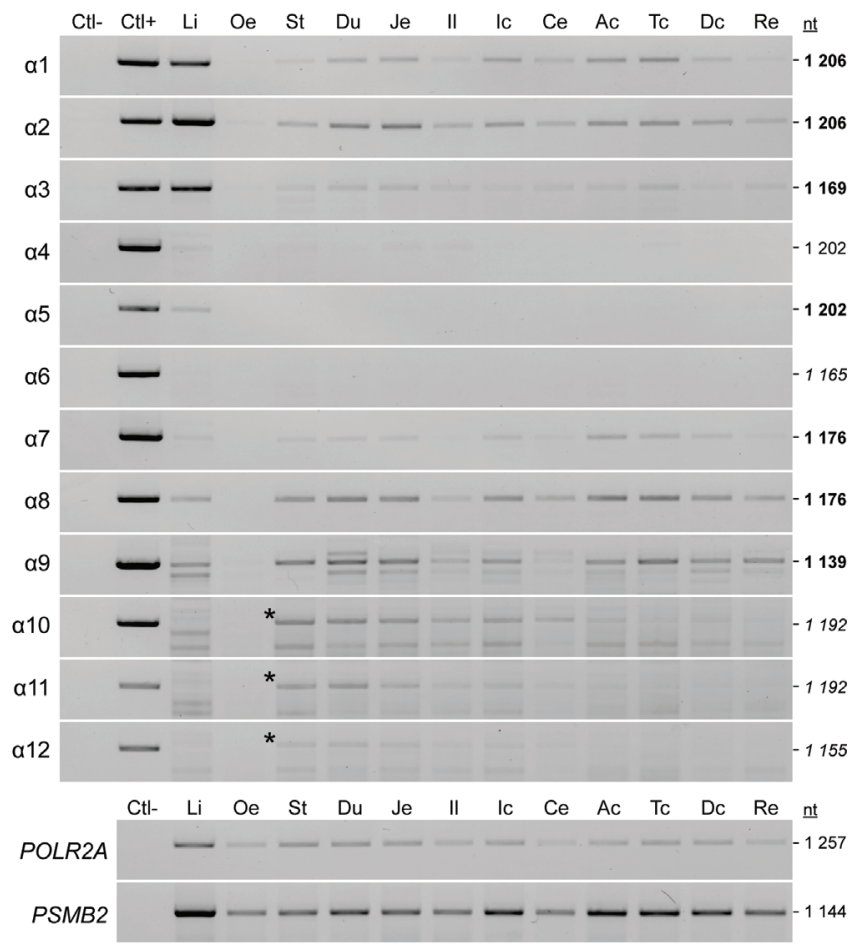

Figure 2: The isoforms of HNF4 $\alpha$ are expressed at varying levels in different tissues of the human gastrointestinal tract. (1 column; 85mm) 
A

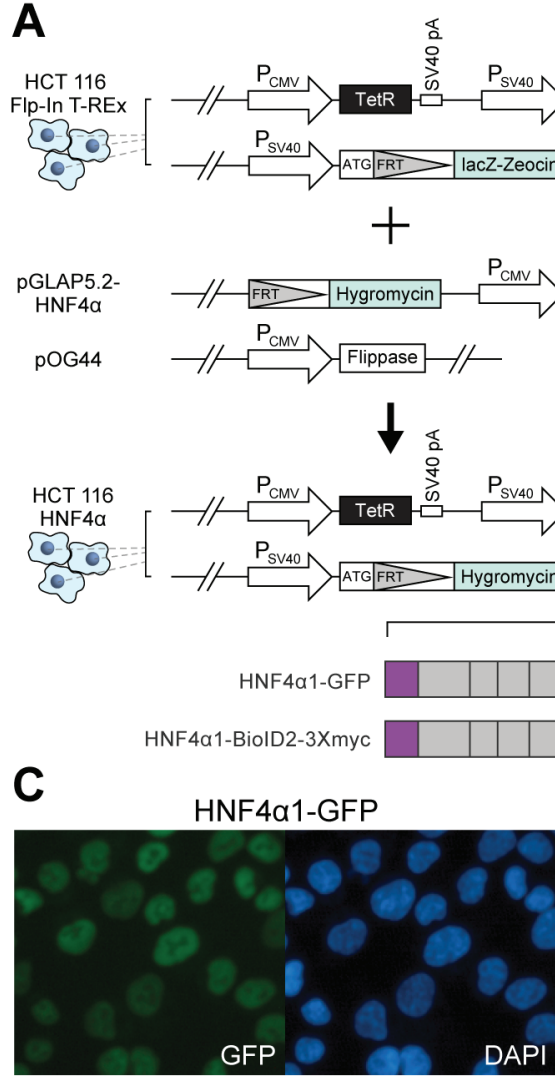

B
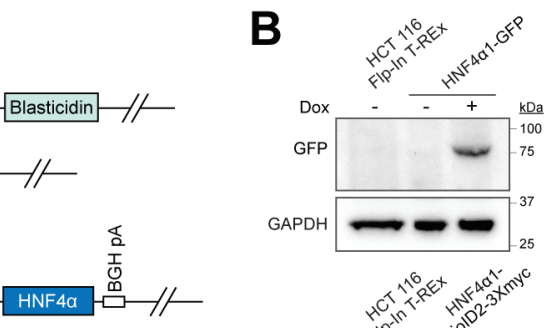

maka

Blasticidin

$$
\text { H }
$$

-
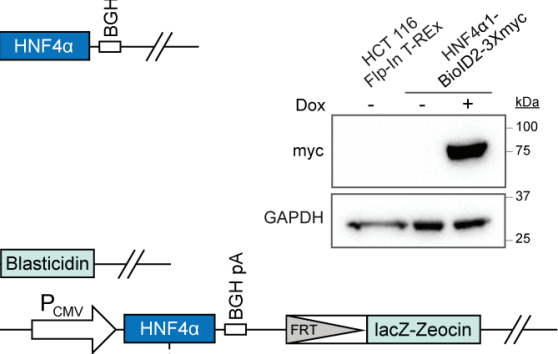

FRT lacZ-Zeocin $/ /$

GFP

BiolD2 $\int_{3 \times m y c}^{\infty}$

HNF4a1-BiolD2-3Xmyc

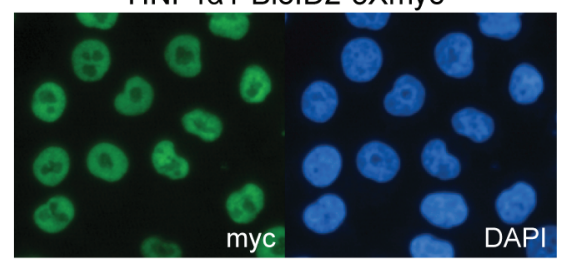

Figure 3: Generation of stable cell lines expressing inducible HNF4a with GFP and BiolD2. (1.5 columns ; $114 \mathrm{~mm}$ ) 

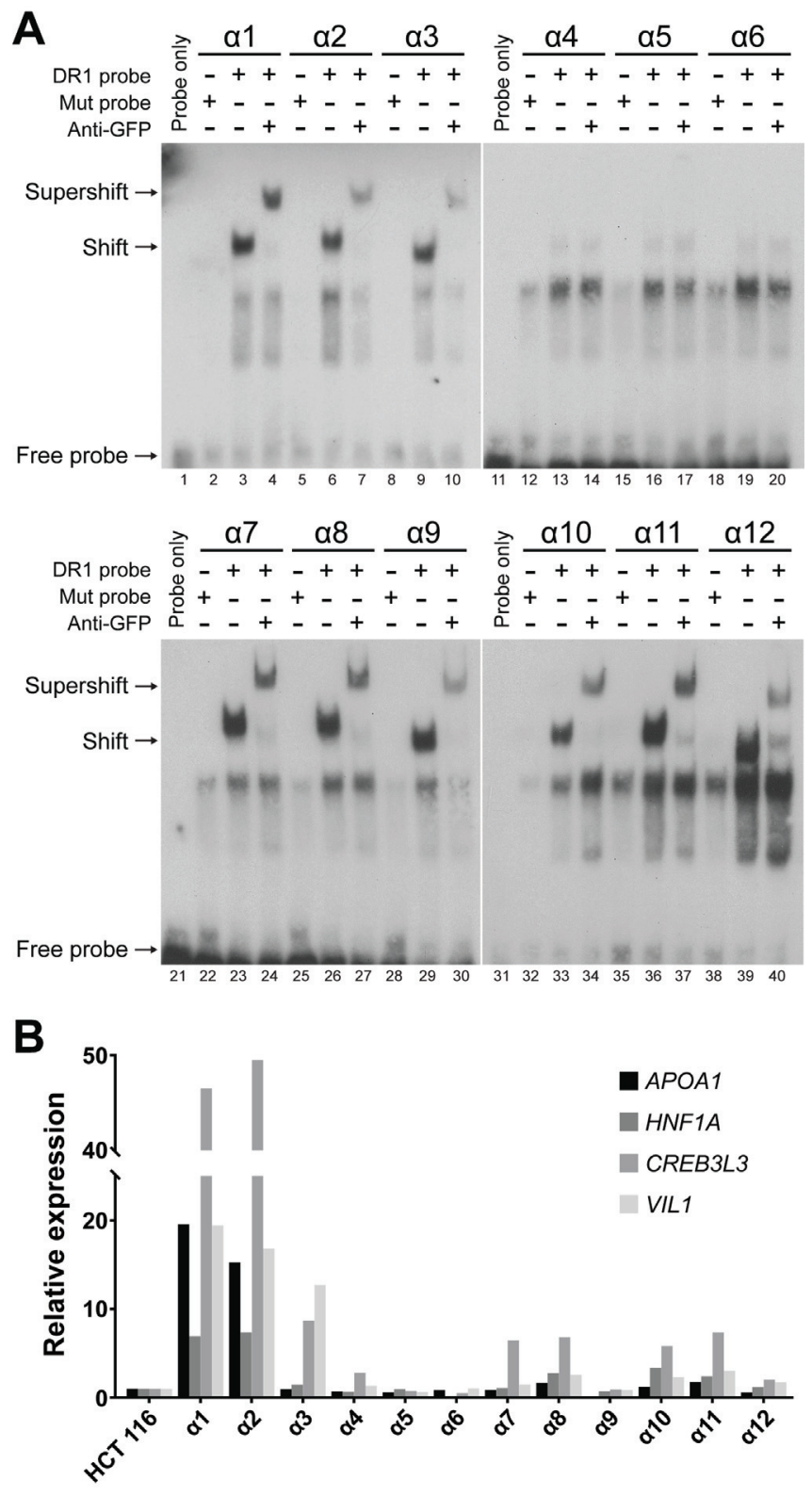

Figure 4: The isoforms of HNF4 $\alpha$ can not all recognize the DR1 consensus response element of the nuclear receptor. (1 column ; 85mm) 
bioRxiv preprint doi: https://doi.org/10.1101/585604; this version posted March 21, 2019. The copyright holder for this preprint (which was not certified by peer review) is the author/funder. All rights reserved. No reuse allowed without permission.

A

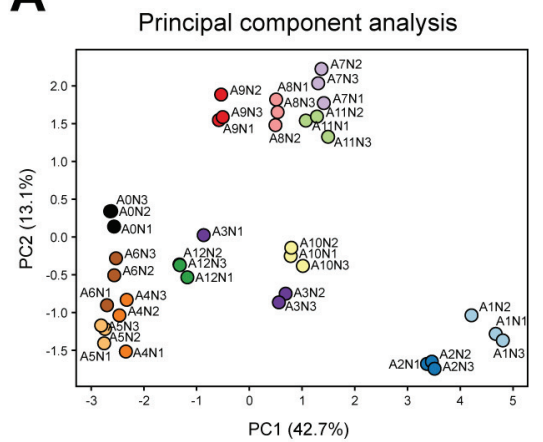

B

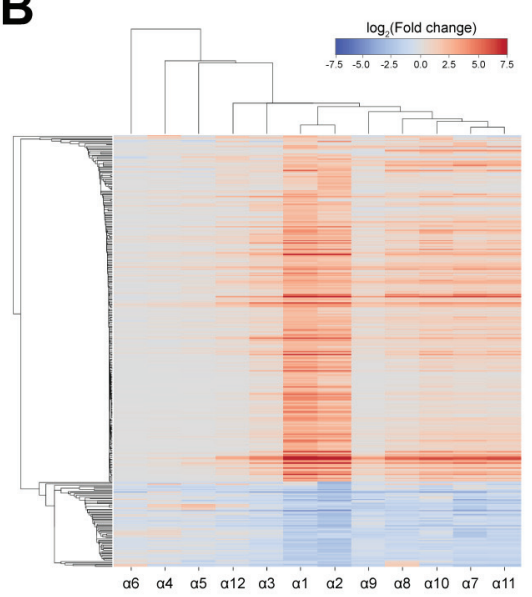

C
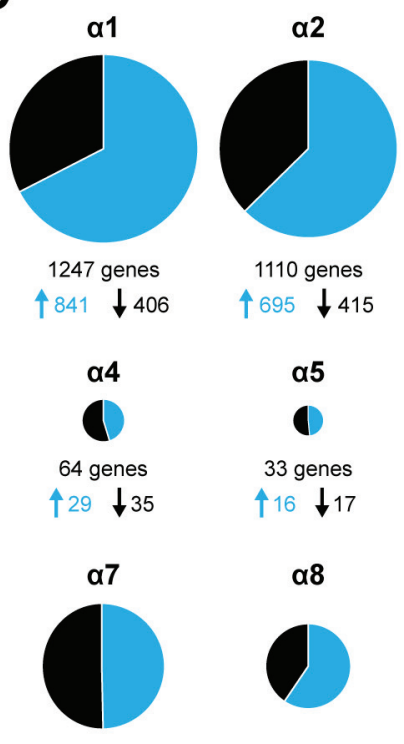

554 genes $\uparrow 275 \downarrow 279$

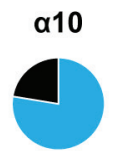

299 genes 个 $232 \downarrow 67$

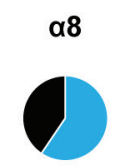

254 genes $\uparrow 151 \downarrow 103$

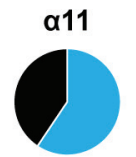

399 genes $\uparrow 237 \downarrow 162$ $\alpha 3$

D

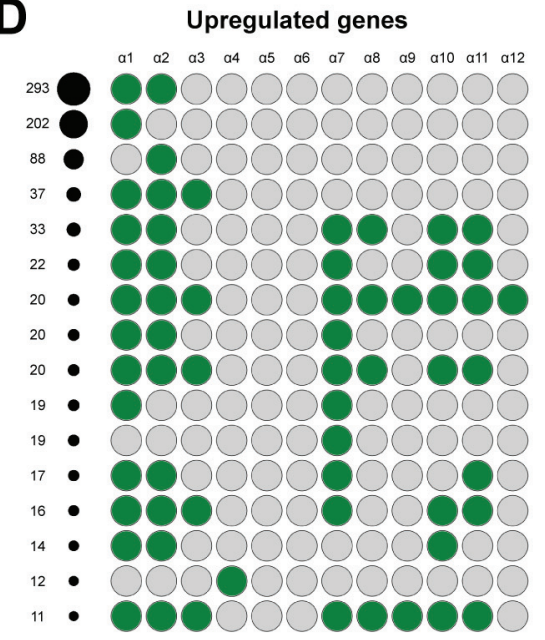

Downregulated genes

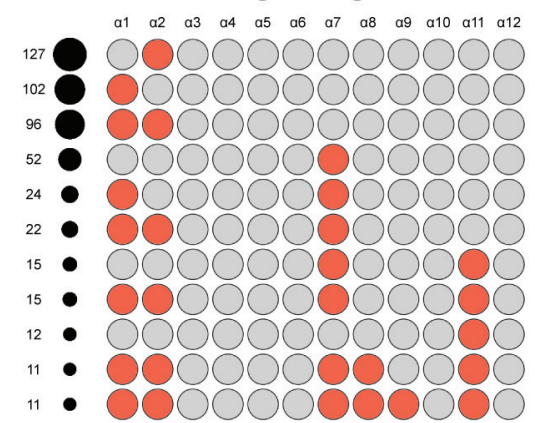

Figure 5: Transcriptomics analysis of HNF4a isoforms by RNAseq. (2 columns ; 174mm) 
bioRxiv preprint doi: https://doi.org/10.1101/585604; this version posted March 21,2019 . The copyright holder for this preprint (which was not certified by peer review) is the author/funder. All rights reserved. No reuse allowed without permission.

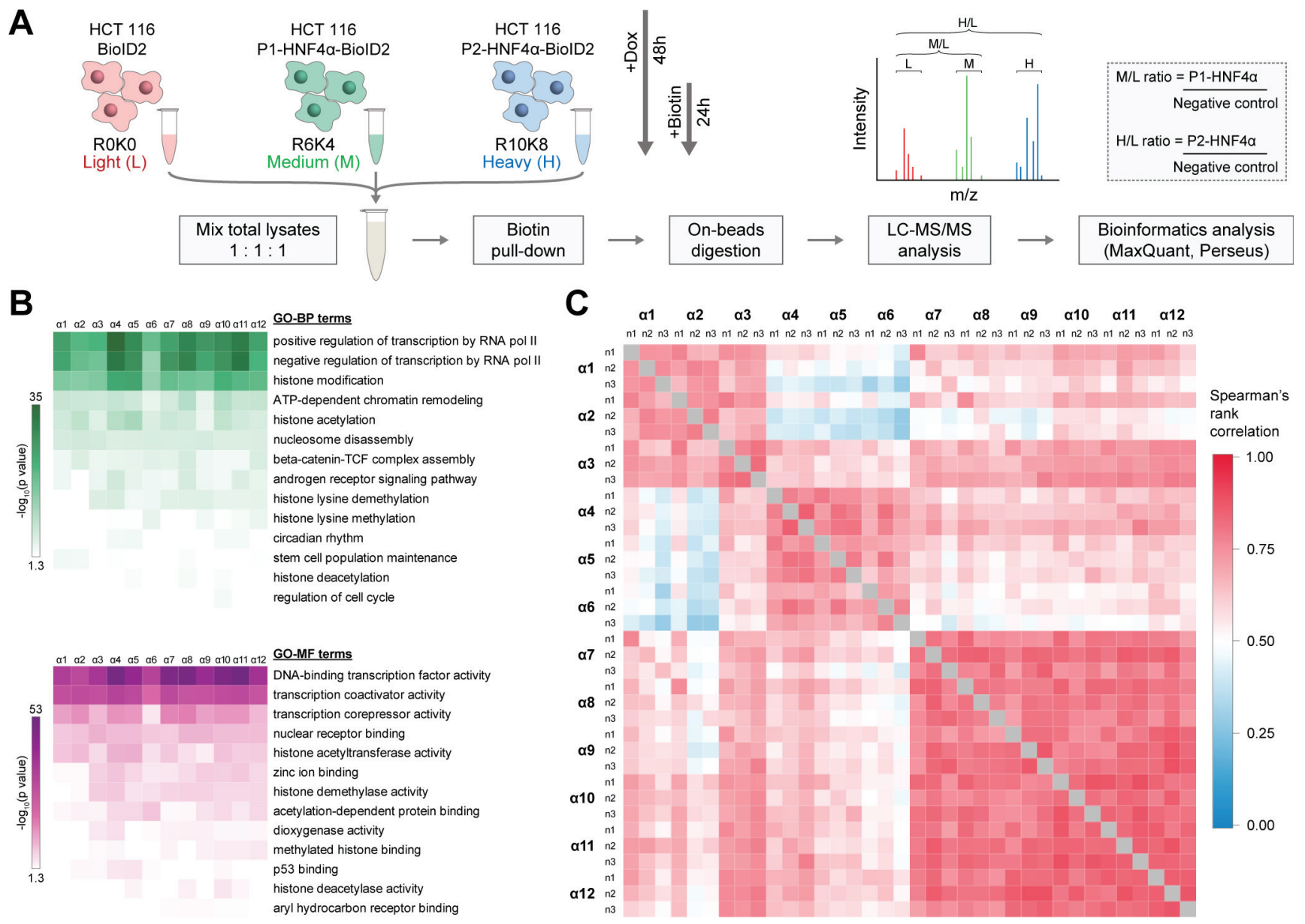

Figure 6: Identification of protein interactions of HFH4 isoforms using the BiolD approach coupled with quantitative mass spectrometry. ( 2 columns ; $174 \mathrm{~mm})$ 
bioRxiv preprint doi: https://doi.org/10.1101/585604; this version posted March 21, 2019. The copyright holder for this preprint (which was not certified by peer review) is the author/funder. All rights reserved. No reuse allowed without permission.

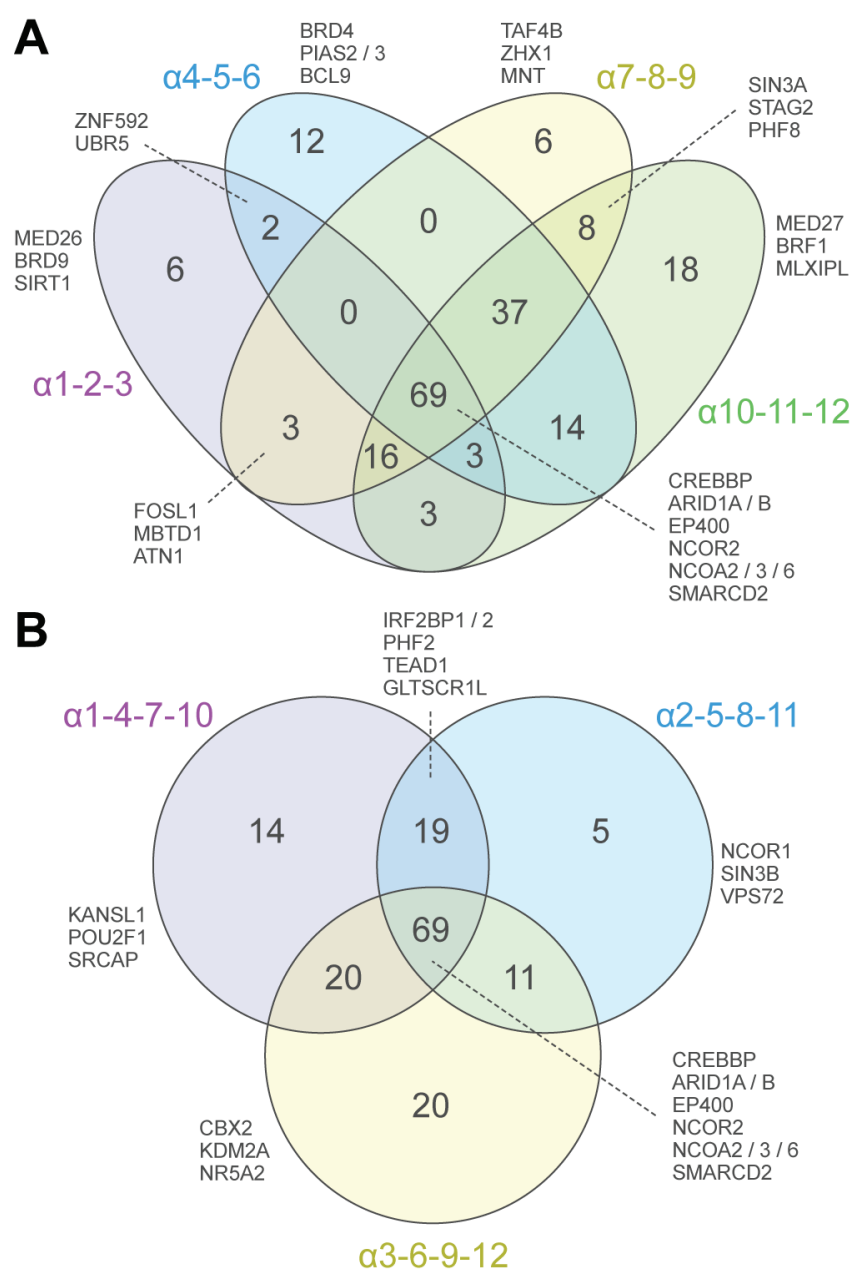

Figure 7: Several proteins specifically interact with isoforms that have a common A / B or F domain.

(1 column ; 85mm) 


\section{SUPPLEMENTARY DATA}

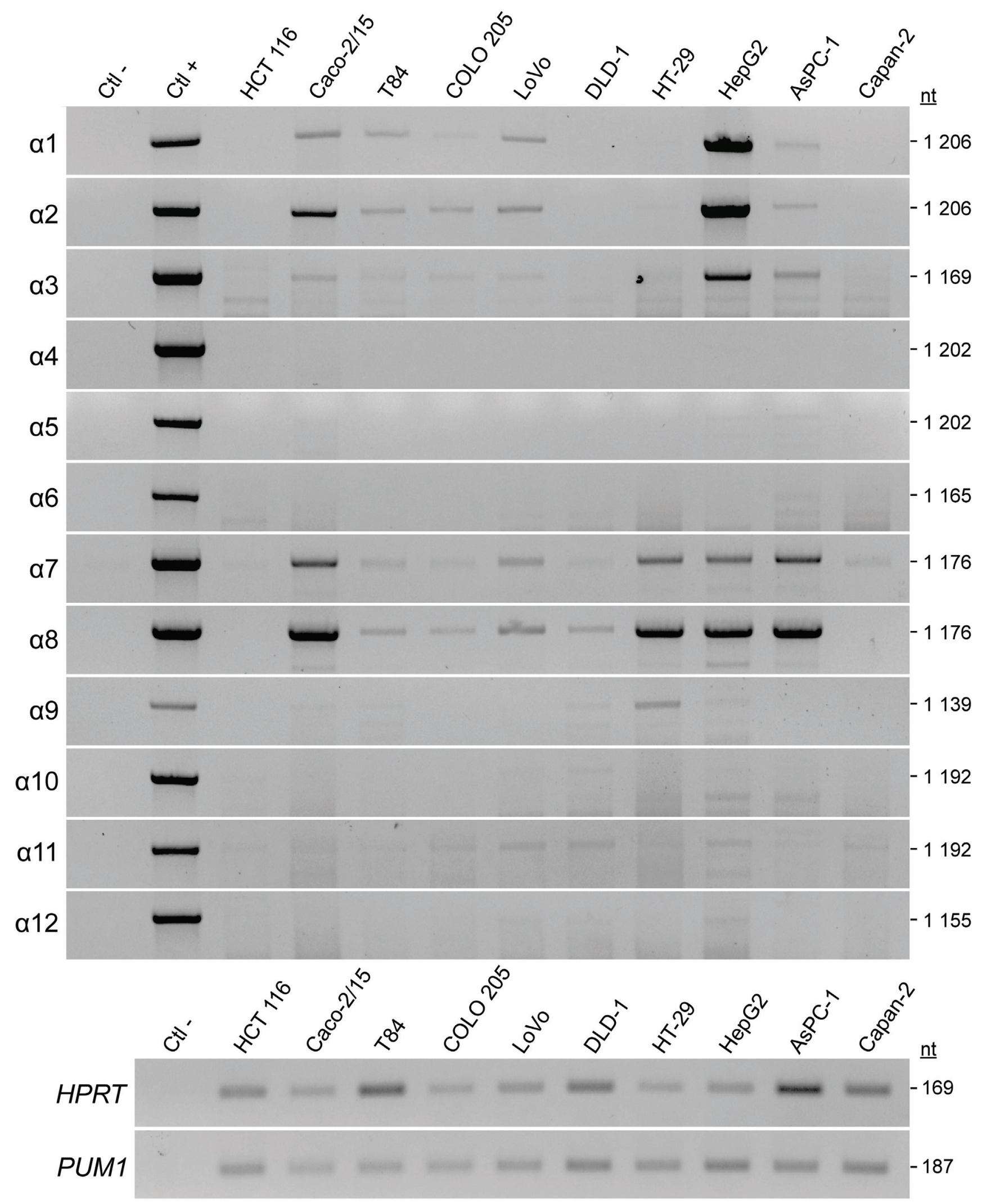

Supplementary Figure 1: The isoforms of HNF4a are expressed at varying levels in different human cancer cell lines. 


\section{HNF4a-GFP isoforms}

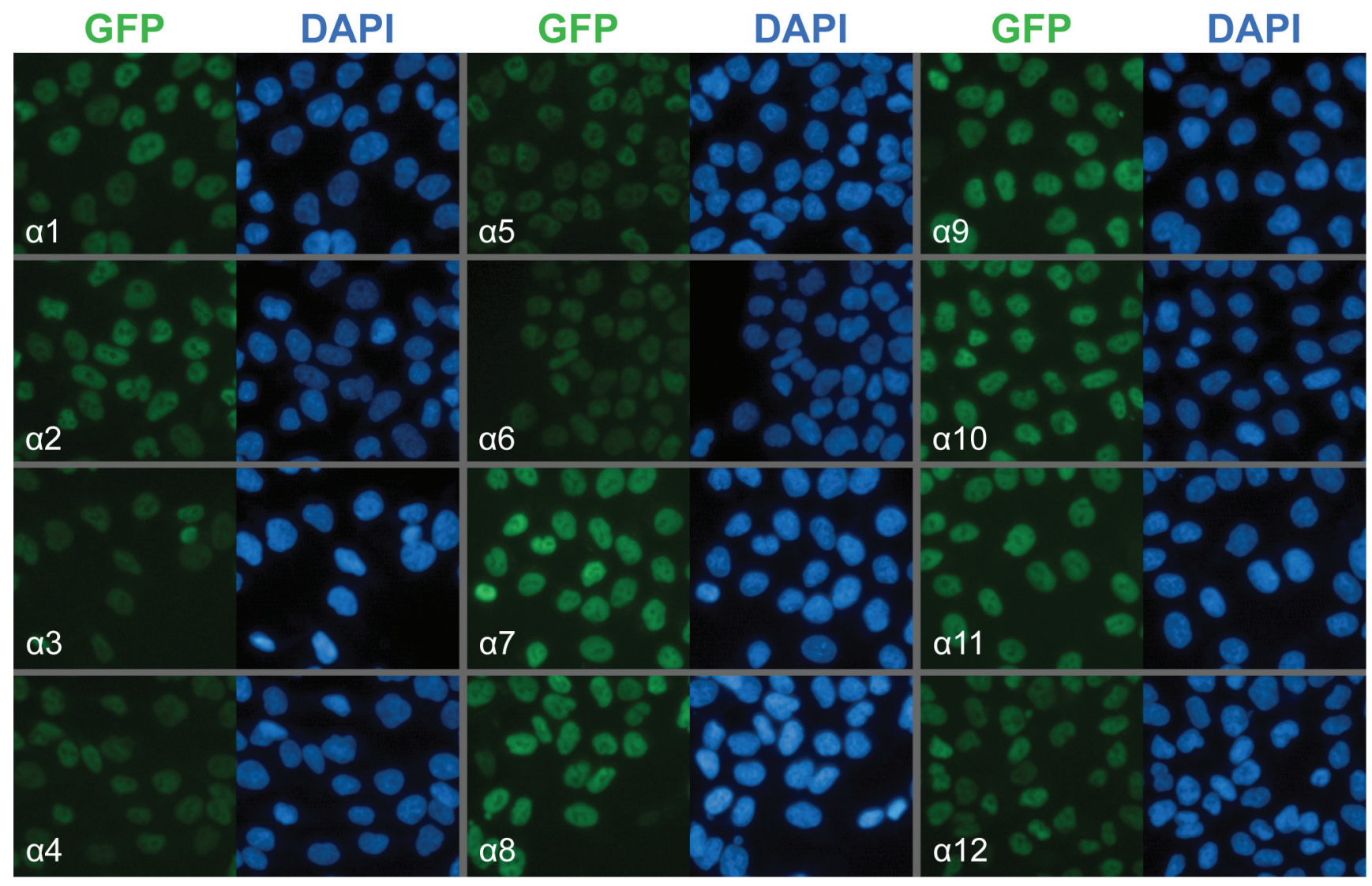

Supplementary Figure 2: GFP-tagged HNF4a localization by immunofluorescence microscopy. 


\section{HNF4a-BiolD2-3Xmyc isoforms}

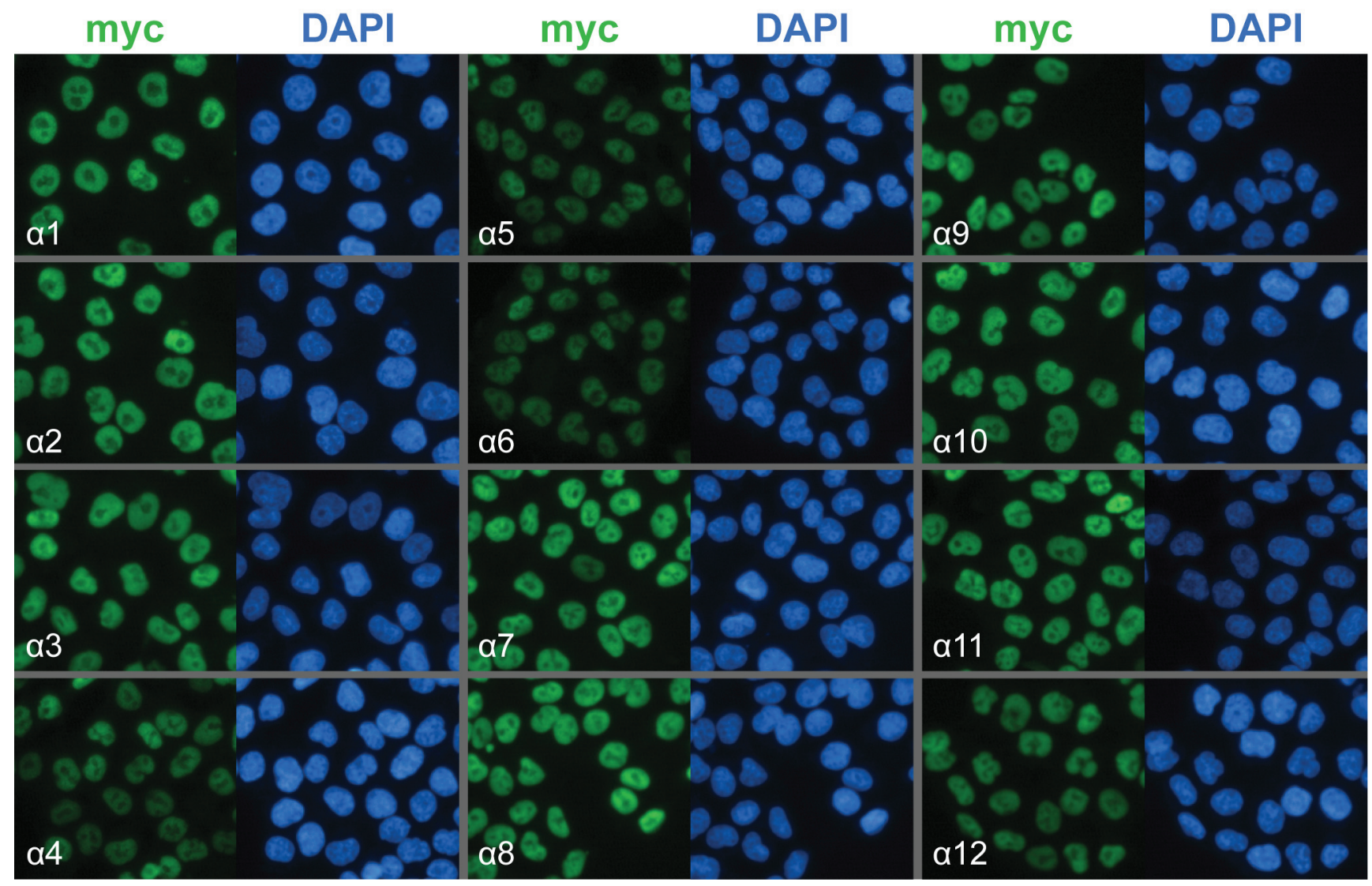

Supplementary Figure 3: 3X mycBiolD2-tagged HNF4a localization by immunofluorescence microscopy. 
A

HNF4a-GFP isoforms
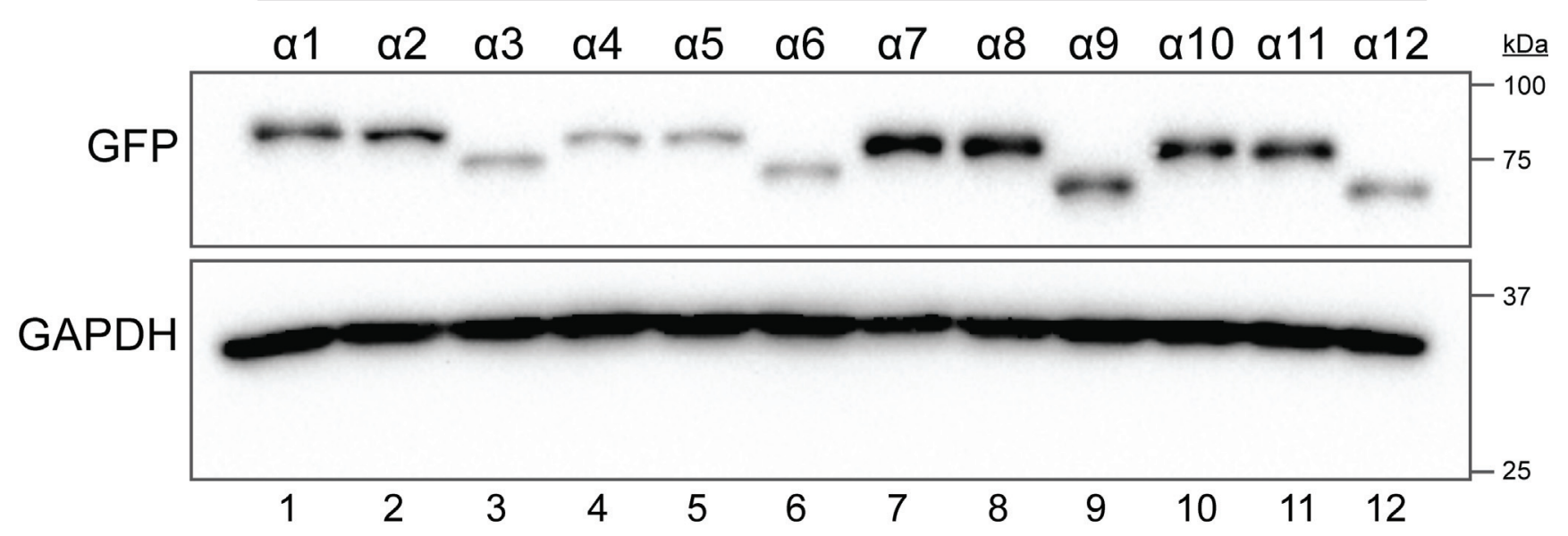

B

\section{HNF4a-BiolD2-3Xmyc isoforms}

Supplementary Figure 4: Protein expression analysis of all 12 stable cell lines (GFP and BiolD2) by immunoblotting. 


\section{GFP}

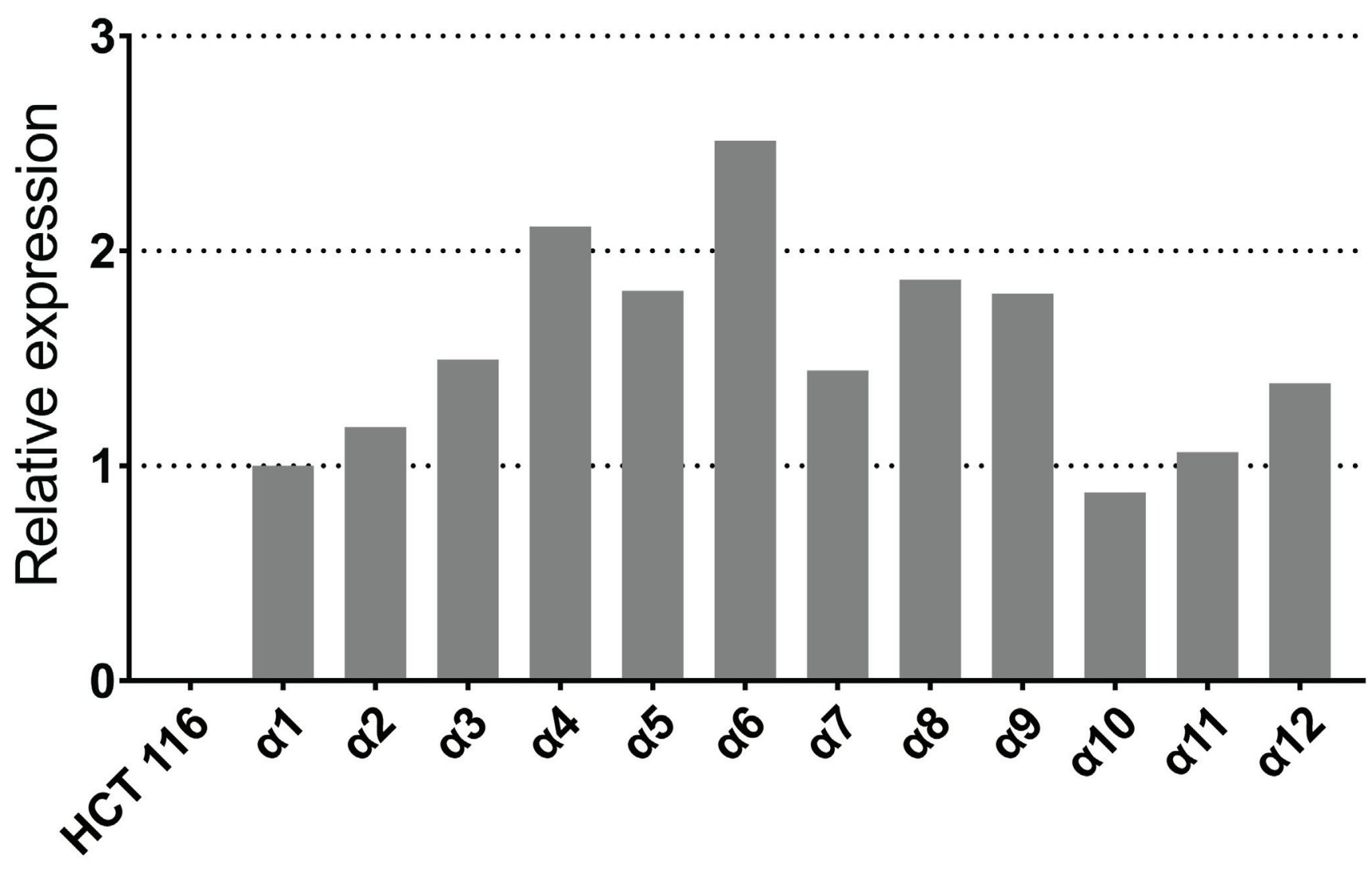

Supplementary Figure 5: Relative mRNA expression of HNF4a isoforms in the stable cell lines. 
$\alpha 1$

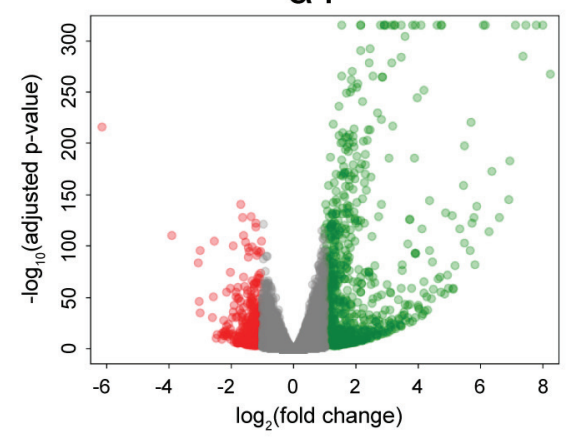

a4

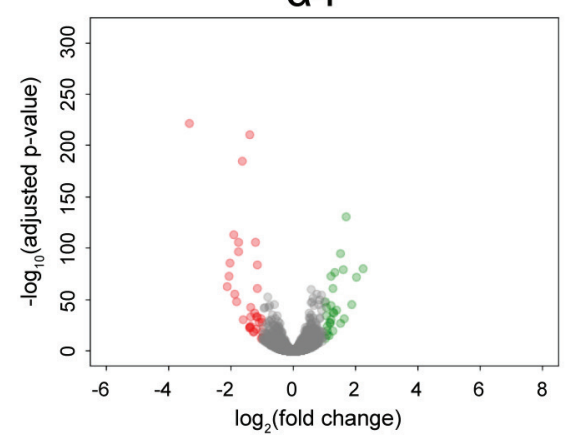

a7

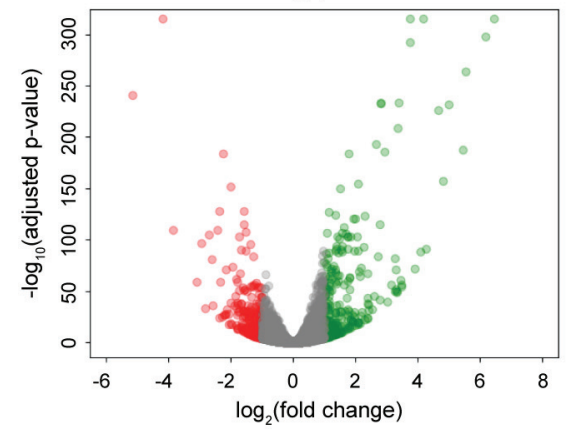

$\alpha 10$

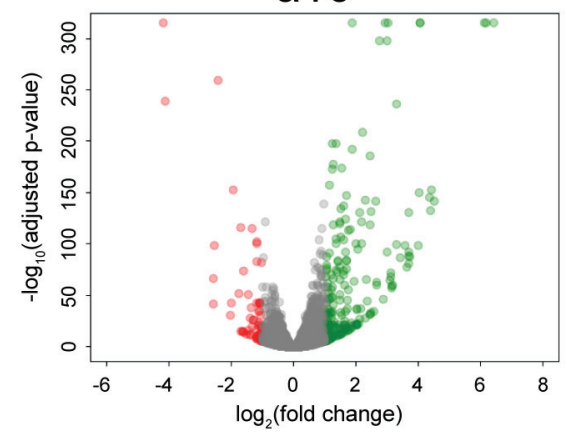

$\alpha 2$

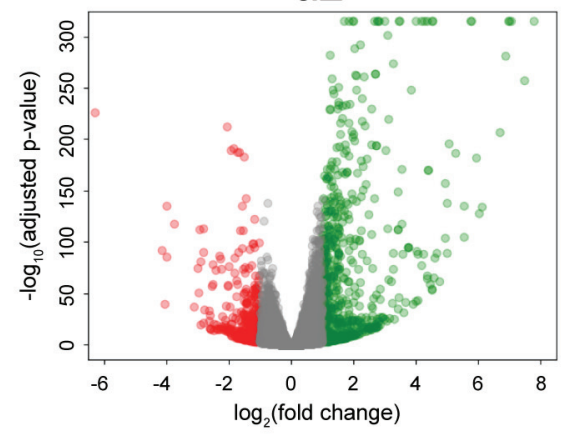

$\alpha 5$

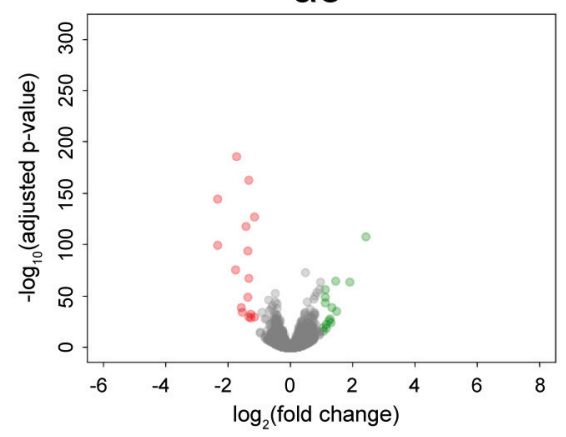

$\alpha 8$

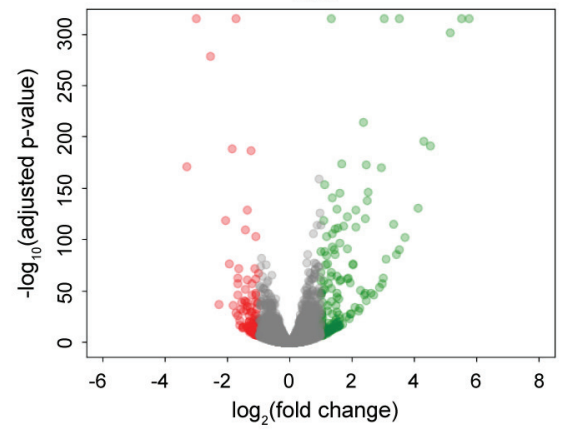

$\alpha 11$

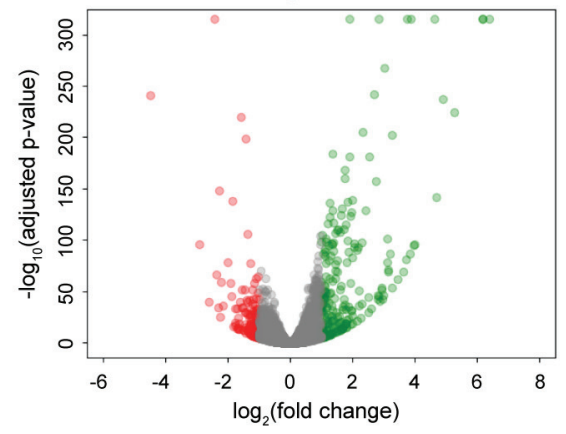

$\alpha 3$

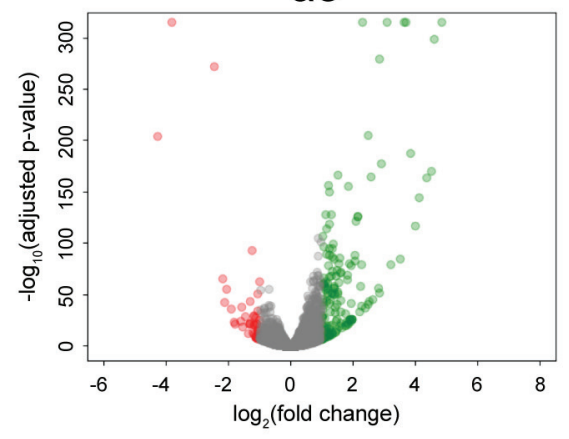

a6

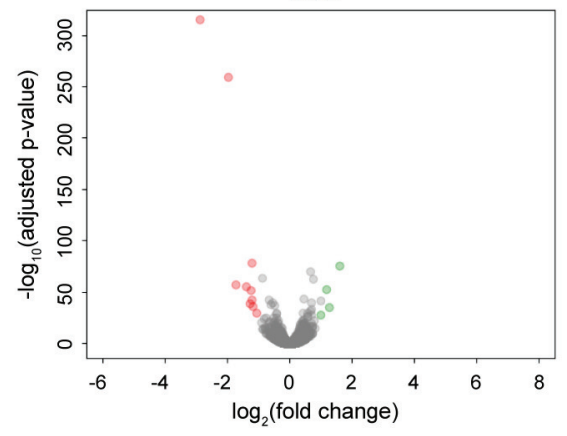

a9

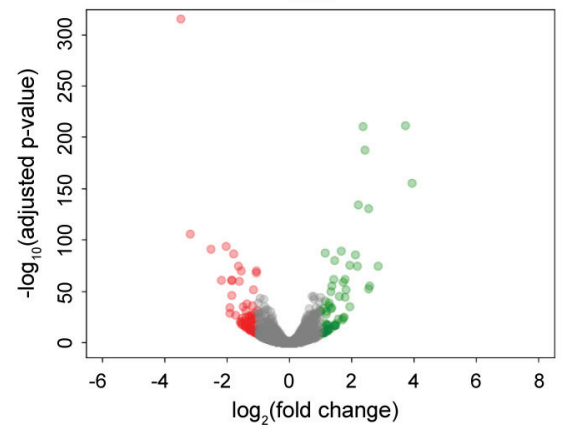

$\alpha 12$

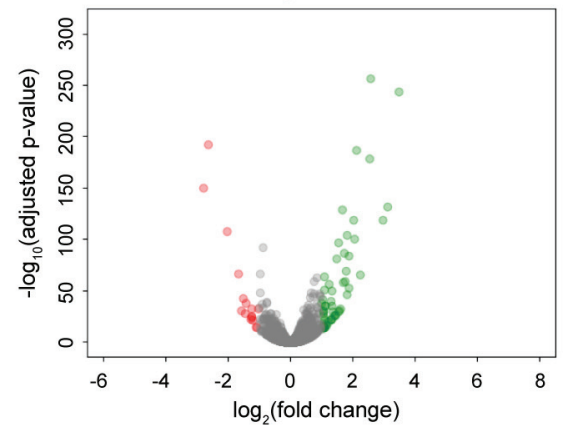

Supplementary Figure 6: Volcano plots of statistical significance against fold-change comparing each HNF4a isoforms with the control. 


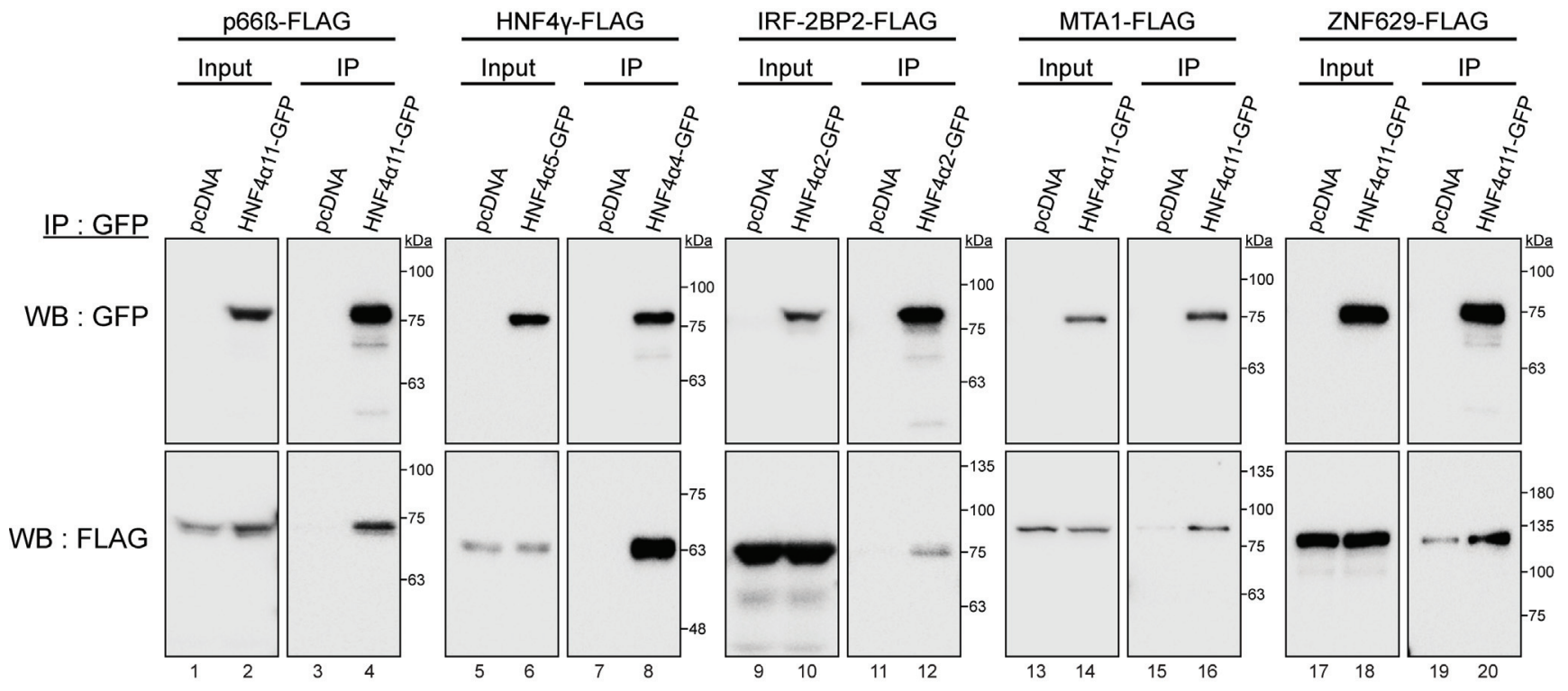

Supplementary Figure 7: Validation of the interactions between the isoforms of HNF4a and five proteins identified by the BiolD approach. 
SWI/SNF chromatin remodeling complexes

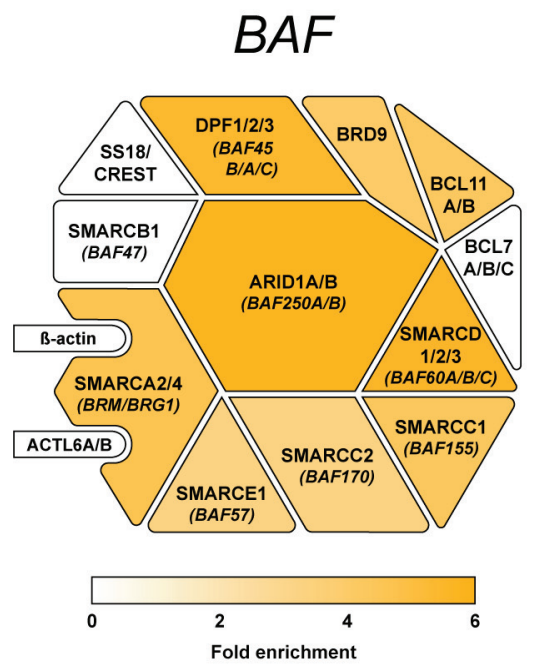

PBAF

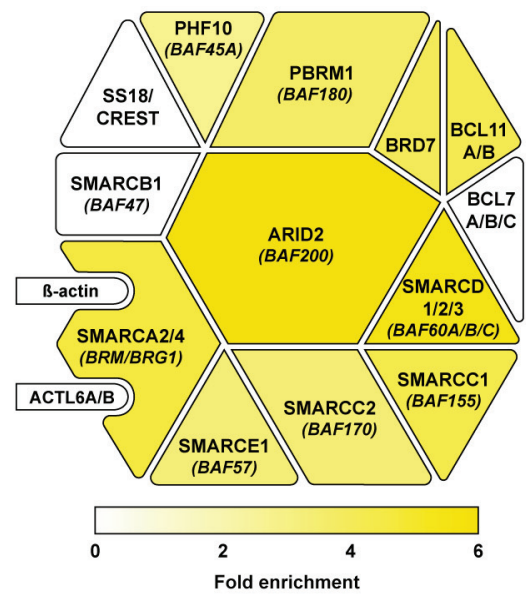

\section{NuRD chromatin remodeling complex}

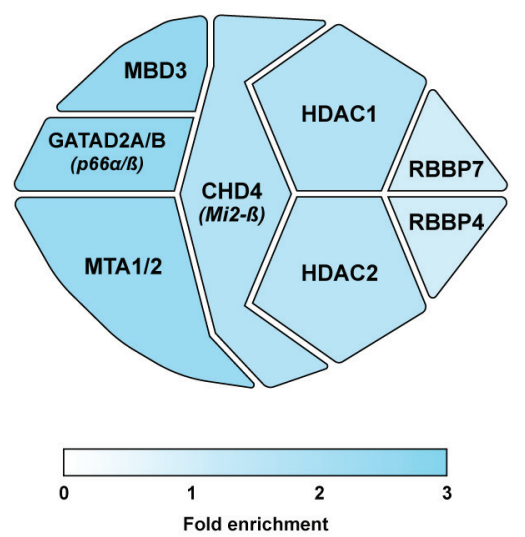

Supplementary Figure 8: Chromatin remodeling complexes identification through BiolD-MS. 
bioRxiv preprint doi: https://doi.org/10.1101/585604; this version posted March 21, 2019. The copyright holder for this preprint (which was not certified by peer review) is the author/funder. All rights reserved. No reuse allowed without permission.

Supplementary Table 1: Identification and annotations of HNF4a isoforms in RefSeq, Uniprot and Ensembl.

\begin{tabular}{|c|c|c|c|c|c|}
\hline \multirow{2}{*}{$\begin{array}{l}\text { HNF4 } \alpha \\
\text { isoform }\end{array}$} & \multirow{2}{*}{ Ref. } & \multirow{2}{*}{$\begin{array}{c}\text { Sequence } \\
\text { length } \\
\text { (a.a.) }\end{array}$} & \multicolumn{3}{|c|}{ Protein IDs and annotations } \\
\hline & & & RefSeq & Uniprot & Ensembl \\
\hline $\mathrm{HNF} 4 \mathrm{\alpha} 1$ & {$[1,2]$} & 464 & $\begin{array}{c}\text { NP_849180.1 } \\
\text { Isoform } 1 \text { (also known as } \\
\text { HNF4alpha1) }\end{array}$ & $\begin{array}{c}\text { P41235-2 } \\
\text { HNF4-Alpha-2 }\end{array}$ & $\begin{array}{c}\text { ENSP00000412111.1 } \\
\text { HNF4A-204 }\end{array}$ \\
\hline $\mathrm{HNF} 4 \alpha 2$ & {$[2,3]$} & 474 & $\begin{array}{c}\text { NP_000448.3 } \\
\text { Isoform } 2 \text { (also known as } \\
\text { HNF4alpha2) }\end{array}$ & $\begin{array}{c}\text { P41235-1 } \\
\text { HNF4-Alpha-1 }\end{array}$ & $\begin{array}{c}\text { ENSP00000312987.3 } \\
\text { HNF4A-201 }\end{array}$ \\
\hline HNF4a3 & [4] & 417 & $\begin{array}{c}\text { NP_849181.1 } \\
\text { Isoform } 3 \text { (also known as } \\
\text { HNF4alpha3) }\end{array}$ & $\begin{array}{c}\text { P41235-3 } \\
\text { HNF4-Alpha-3 }\end{array}$ & $\begin{array}{c}\text { ENSP00000410911.2 } \\
\text { HNF4A-205 }\end{array}$ \\
\hline $\begin{array}{l}\text { HNF4a4 } \\
\text { (putative) }\end{array}$ & - & 457 & - & - & - \\
\hline HNF4a5 & [5] & 467 & $\begin{array}{c}\text { NP_001245284.1 } \\
\text { Isoform } 7\end{array}$ & $\begin{array}{c}\text { P41235-4 } \\
\text { HNF4-Alpha-4* }\end{array}$ & - \\
\hline $\begin{array}{l}\text { HNF4a6 } \\
\text { (putative) }\end{array}$ & - & 420 & - & - & - \\
\hline $\mathrm{HNF} 4 \alpha 7$ & {$[6,7]$} & 442 & $\begin{array}{c}\text { NP_001025174.1 } \\
\text { Isoform 4 (also known as } \\
\text { HNF4alpha7) }\end{array}$ & $\begin{array}{c}\text { P41235-6 } \\
\text { HNF4-Alpha-8 }\end{array}$ & $\begin{array}{c}\text { ENSP00000396216.1 } \\
\text { HNF4A-206 }\end{array}$ \\
\hline HNF4a8 & {$[8,9]$} & 452 & $\begin{array}{c}\text { NP_787110.2 } \\
\text { Isoform } 5 \text { (also known as } \\
\text { HNF4alpha8) }\end{array}$ & $\begin{array}{c}\text { P41235-5 } \\
\text { HNF4-Alpha-7 }\end{array}$ & $\begin{array}{c}\text { ENSP00000315180.4 } \\
\text { HNF4A-202 }\end{array}$ \\
\hline $\mathrm{HNF} 4 \alpha 9$ & {$[9,10]$} & 395 & $\begin{array}{c}\text { NP_001025175.1 } \\
\text { Isoform } 6 \text { (also known as } \\
\text { HNF4alpha9) }\end{array}$ & $\begin{array}{c}\text { P41235-7 } \\
\text { HNF4-Alpha-9 }\end{array}$ & $\begin{array}{c}\text { ENSP00000476609.1 } \\
\text { HNF4A-208 }\end{array}$ \\
\hline HNF4a10 & {$[11]$} & 439 & $\begin{array}{c}\text { NP_001274111.1 } \\
\text { Isoform } 8 \text { (also known as } \\
\text { HNF4alpha10) }\end{array}$ & $\begin{array}{c}\text { B9WT8 } \\
\text { HNF4alpha10/11/12 } \\
\text { Partial sequence }\end{array}$ & $\begin{array}{c}\text { ENSP00000476310.1 } \\
\text { HNF4alpha10/11/12 } \\
\text { Partial sequence }\end{array}$ \\
\hline HNF4a11 & [11] & 449 & $\begin{array}{c}\text { NP_001274112.1 } \\
\text { Isoform } 9 \text { (also known as } \\
\text { HNF4alpha11) }\end{array}$ & $\begin{array}{l}\text { A0A087WXV4 } \\
\text { Hepatocyte nuclear } \\
\text { factor 4-alpha }\end{array}$ & $\begin{array}{c}\text { ENSP00000481331.1 } \\
\text { HNF4A-209 }\end{array}$ \\
\hline HNF4a12 & [11] & 392 & $\begin{array}{c}\text { NP_001274113.1 } \\
\text { Isoform } 10 \text { (also known as } \\
\text { HNF4alpha12) }\end{array}$ & - & - \\
\hline
\end{tabular}

* Incorrect sequence of 504 a.a. (not using the alternate downstream start codon compared to HNF4a1-2-3)

+ Partial sequence of 107 a.a. covering the $\mathrm{NH}_{2}$ domain common for HNF4a10-11-12

‡ Complete sequence for HNF4a11, not in the annotation 
bioRxiv preprint doi: https://doi.org/10.1101/585604; this version posted March 21, 2019. The copyright holder for this preprint (which was not certified by peer review) is the author/funder. All rights reserved. No reuse allowed without permission.

Supplementary Table 2: RNAseq results (gene name, intensities, fold change, p-values). See attached file: Supp_Table2_RNAseq_results.xIsx 
bioRxiv preprint doi: https://doi.org/10.1101/585604; this version posted March 21, 2019. The copyright holder for this preprint (which was not certified by peer review) is the author/funder. All rights reserved. No reuse allowed without permission.

Supplementary Table 3: RNAseq quality control statistics See attached file: Supp_Table3_RNAseq_QC_stats.xIsx 
Supplementary Table 4: Details for the different SILAC label combinations.

\begin{tabular}{|c|c|c|c|}
\hline & Light (ROKO) & Medium (R6K4) & Heavy (R10K8) \\
\hline $\begin{array}{c}\# \\
\text { sample }\end{array}$ & $\begin{array}{c}\text { HCT } 116 \\
\text { BiolD2 }\end{array}$ & $\begin{array}{c}\text { HCT } 116 \\
\text { P1-HNF4a- } \\
\text { BiolD2-3Xmyc }\end{array}$ & $\begin{array}{c}\text { HCT } 116 \\
\text { P2-HNF4a- } \\
\text { BiolD2-3Xmyc }\end{array}$ \\
\hline 1 & Negative control & HNF4a1 & HNF4a7 \\
\hline 2 & Negative control & HNF4a2 & HNF4a8 \\
\hline 3 & Negative control & HNF4a3 & HNF4a9 \\
\hline 4 & Negative control & HNF $4 a 5$ & HNF4a10 \\
\hline 5 & Negative control & HNF4a4 & HNF4a11 \\
\hline 6 & Negative control & HNF4a6 & HNF4a12 \\
\hline
\end{tabular}


bioRxiv preprint doi: https://doi.org/10.1101/585604; this version posted March 21, 2019. The copyright holder for this preprint (which was not certified by peer review) is the author/funder. All rights reserved. No reuse allowed without permission.

Supplementary Table 5: Mass spectrometry data for each of the HNF4a isoforms.

See attached file: Supp_Table5_BiolD-MS_results.xIsx 
Supplementary Table 6: Semi-quantitative RT-PCR primers.

\begin{tabular}{|c|c|c|c|}
\hline Gene & $\begin{array}{l}\text { HNF4a } \\
\text { isoform }\end{array}$ & 5' primer sequence & 3' primer sequence \\
\hline \multirow{12}{*}{ HNF4A } & HNF4a1 & $\begin{array}{l}\text { CAG CCT ACA CCA CCC TGG } \\
\text { AAT TTG }\end{array}$ & $\begin{array}{l}\text { GGG TCT CAG GGG TGG ACA } \\
\text { TC }\end{array}$ \\
\hline & HNF4a2 & $\begin{array}{l}\text { CAG CCT ACA CCA CCC TGG } \\
\text { AAT TTG }\end{array}$ & $\begin{array}{l}\text { GTC GGG GCC ACT CAC ACA } \\
\text { TC }\end{array}$ \\
\hline & HNF4a3 & $\begin{array}{l}\text { CAG CCT ACA CCA CCC TGG } \\
\text { AAT TTG }\end{array}$ & $\begin{array}{l}\text { CAG TGG GGA AGC CAA GGA } \\
\text { GC }\end{array}$ \\
\hline & HNF4a4 & $\begin{array}{l}\text { CCG ACA TCA CTG GAG CAT } \\
\text { ATC TGG AG }\end{array}$ & $\begin{array}{l}\text { GGG TCT CAG GGG TGG ACA } \\
\text { TC }\end{array}$ \\
\hline & HNF4a5 & $\begin{array}{l}\text { CCG ACA TCA CTG GAG CAT } \\
\text { ATC TGG AG }\end{array}$ & $\begin{array}{l}\text { GTC GGG GCC ACT CAC ACA } \\
\text { TC }\end{array}$ \\
\hline & HNF4a6 & $\begin{array}{l}\text { CCG ACA TCA CTG GAG CAT } \\
\text { ATC TGG AG }\end{array}$ & $\begin{array}{l}\text { CAG TGG GGA AGC CAA GGA } \\
\text { GC }\end{array}$ \\
\hline & $\mathrm{HNF} 4 \alpha 7$ & $\begin{array}{l}\text { GGG CTC CAG TGG AGA GTT } \\
\text { CTT ACG }\end{array}$ & $\begin{array}{l}\text { GGG TCT CAG GGG TGG ACA } \\
\text { TC }\end{array}$ \\
\hline & HNF4a8 & $\begin{array}{l}\text { GGG CTC CAG TGG AGA GTT } \\
\text { CTT ACG }\end{array}$ & $\begin{array}{l}\text { GTC GGG GCC ACT CAC ACA } \\
\text { TC }\end{array}$ \\
\hline & HNF4a9 & $\begin{array}{l}\text { GGG CTC CAG TGG AGA GTT } \\
\text { CTT ACG }\end{array}$ & $\begin{array}{l}\text { CAG TGG GGA AGC CAA GGA } \\
\text { GC }\end{array}$ \\
\hline & HNF4a10 & ATG TCG GAC TGG GGC CAG & $\begin{array}{l}\text { GGG TCT CAG GGG TGG ACA } \\
\text { TC }\end{array}$ \\
\hline & HNF4a11 & ATG TCG GAC TGG GGC CAG & $\begin{array}{l}\text { GTC GGG GCC ACT CAC ACA } \\
\text { TC }\end{array}$ \\
\hline & HNF4a12 & ATG TCG GAC TGG GGC CAG & $\begin{array}{l}\text { CAG TGG GGA AGC CAA GGA } \\
\text { GC }\end{array}$ \\
\hline HPRT & & $\begin{array}{l}\text { ACC AGT CAA CAG GGG ACA } \\
\text { TAA }\end{array}$ & $\begin{array}{l}\text { CTT CGT GGG GTC CTT TTC } \\
\text { ACC }\end{array}$ \\
\hline POLR2A & & $\begin{array}{l}\text { GAT TGT GAA TGG GGA TGA } \\
\text { CC }\end{array}$ & ATA AGC ACG TCC ACC GTT TC \\
\hline PSMB2 & & GCC CCG ACT ATG TTC TTG TC & $\begin{array}{l}\text { GTC AGG ATG GTC TCG CTC } \\
\text { TC }\end{array}$ \\
\hline PUM1 & & TGA GGT GTG CAC CAT GAA C & $\begin{array}{l}\text { CAG AAT GTG CTT GCC ATA } \\
\text { GG }\end{array}$ \\
\hline
\end{tabular}


bioRxiv preprint doi: https://doi.org/10.1101/585604; this version posted March 21, 2019. The copyright holder for this preprint (which was not certified by peer review) is the author/funder. All rights reserved. No reuse allowed without permission.

23

Supplementary Table 7: Real-time RT-PCR primers.

\begin{tabular}{|l|l|l|}
\hline \multicolumn{1}{|c|}{ Gene } & \multicolumn{1}{c|}{$\mathbf{5}^{\prime}$ primer sequence } & \multicolumn{1}{c|}{ 3' primer sequence } \\
\hline APOA1 & TGG ATG TGC TCA AAG ACA GC & CCA GAT CCT TGC TCA TCT CC \\
\hline CREB3L3 & CCT GGA GAC TCG GAT GTC AG & GCA AAG GAC AGC AAC AGG AC \\
\hline EGFP & ACG TAA ACG GCC ACA AGT TC & AAG TCG TGC TGC TTC ATG TG \\
\hline HNF1A & GCA CAG CTT GGA GCA GAC AT & GTT GAT GAC CGG CAC ACT CT \\
\hline VIL1 & AGC CAG ATC ACT GCT GAG GT & AGG TGT TCC TCC TTC CTG CT \\
\hline TBP & GGG GAG CTG TGA TGT GAA GT & GGA GAA CAA TTC TGG GTT TGA \\
\hline
\end{tabular}

